\title{
RECONOCIMIENTO CONSTITUCIONAL DE LA DIGNIDAD, INDIVIDUALIDAD $Y$ DERECHOS DE LA PERSONALIDAD ${ }^{1}$
}

POR

\author{
MIGUEL ÁNGEL ALEGRE MARTÍNEZ \\ Universidad de León \\ ÓSCAR MAGO BENDAHÁN \\ Universidad Central de Venezuela
}

\section{CONSIDERACIONES PREVIAS Y PLANTEAMIENTO GENERAL}

En estos años tan convulsos que nos está deparando el inicio del siglo XXI, bajo la sensación de que la historia se está escribiendo cada día, con rapidez e intensidad jamás conocidas, la necesidad de volver la mirada hacia la persona como centro y objeto principal de la reflexión ju-

\footnotetext{
1 Estas páginas son anticipo y punto de partida de un trabajo más amplio que actualmente preparan los autores, bajo el título Derechos de la personalidad y daños morales (marco teórico y mecanismos de protección en Latinoamérica y España). Se incorporan además algunas reflexiones contenidas en un trabajo anterior de Miguel Ángel Alegre MARTíNeZ, titulado "El reconcimiento constitucional de la dignidad humana: significado y alcance", e incluido en el Libro Homenaje al Profesor Íñigo Cavero, de próxima aparición. Una versión reducida de este trabajo fue expuesta en una Conferencia-Seminario que tuvo lugar en mayo de 2005, en la Universitat Jaume I de Castellón.
} 
rídica se revela de manera más apremiante que nunca. En efecto, y a nuestro juicio, el afán por seguir el curso de los acontecimientos, y el análisis de los mismos con arreglo a magnitudes macroscópicas (el Estado y la soberanía, la evolución de sus formas e instituciones...), sólo puede entenderse al servicio de un objetivo bien determinado: adaptar el nuevo escenario al ser humano, delimitar con precisión sus coordenadas en aras a fortalecer su posición, no ya únicamente como titular de derechos, deberes y libertades, sino además como sujeto con nuevas necesidades e intereses, que se enfrenta a problemas y dificultades hasta ahora inimaginables.

Para ello resultará imprescindible, por una parte, tomar como punto de partida el poder transformador (ALEGRE MARTíNEZ, 2005: 53-55) de una Constitución que, de manera especial en el momento presente, "aparece como referencia inexcusable para el mantenimiento de los valores y supuestos que conforman una convivencia civilizada", y "como instrumento legitimador de un mundo confuso, desordenado y caótico" (DE VegA GARCíA, 1998: 84). Pero además, será necesario tener presente, con el mismo autor, que "de igual manera que la misión del médico es curar la enfermedad y no ocultarla, la misión del jurista no puede ser otra que la de, recurriendo al razonamiento crítico, denunciar los problemas que la realidad presenta, y no disolverlos en ejercicios de tecnicismo inocuo para ignorarlos". Lo contrario implicaría forjar "un Derecho Constitucional como gran construcción técnica y avalorativa», en el que preocupen más "los temas que los problemas", renunciando a ampliar el horizonte hacia "las cuestiones alusivas a la propia fundamentación y legitimidad de toda la estructura constitucional» (cfr. DE Vega García, 1997, 702 y 704).

Partiendo de estas premisas, nuestra mirada ha de dirigirse necesariamente hacia la dignidad de la persona como "principio fundamentador de los derechos humanos [...] y, en consecuencia, concepto central en la cimentación de todo el edificio constitucional" (MATEO PARDO, 1993: 341), y hacia los derechos de la personalidad, "íntimamente relacionados con el valor de la dignidad humana", que "pertenecen a la persona en cuanto tal y, en consecuencia, su disfrute no puede verse condicionado por la subsistencia de condiciones jurídicas particulares" (RoLLA, 2002: 478)'.

2 Por eso, y a la vista de las circunstancias que estamos describiendo, resulta especialmente gratificante comprobar que, en los últimos tiempos, está volviendo a cobrar impulso el estudio y la reflexión en torno a la dignidad de la persona, dando así continuidad y aportando nuevos elementos a una línea de trabajo que otros hemos venido desarrollando. Así, por citar sólo algunos ejemplos en el panorama doc- 
De esta manera, la dignidad humana, los derechos de la personalidad derivados de la misma, y el libre desarrollo de la personalidad como proyección y exigencia que se sigue inevitablemente de ambos, son los elementos que nos sugieren las dos ideas-fuerza que bien pueden servir como leitmotiv o hilo conductor de este trabajo:

a) Desde el momento en que se opta por constitucionalizar la dignidad como característica y atributo inseparable de la persona ${ }^{3}$, los

trinal español, trabajos como los de GARcíA GARcía (2003), GutiÉRREZ GutiÉRREZ (2004) o Prieto Álvarez (2005) vienen a sumarse a los que, también desde muy diversas perspectivas, se habían venido ocupando del tema; entre ellos pueden mencionarse, sin afán de exhaustividad, los de González PÉrez (1986), MATEO PARdo (1993), FERnÁndez Segado (1995), Ruiz Miguel (1995), Alegre Martínez (1995, 1996), Ruiz-Giménez Cortés (1997), Carrillo Salcedo (1999), Marina y De la Válgoma (2000), Cándido (2001), o PeCes-Barba Martínez (2002). Asimismo, de entre los trabajos de autores no españoles, baste recordar en este momento los de VON MÜNCH (1982), SPAEMANN (1998), Benda (2001), LANDA ARRoyo (2002) y RolLa (2002).

3 Como hemos recordado en otros trabajos (Alegre MARTínez, 1996: 61-62, 131; 2005: 43 y ss., y la bibliografía allí citada), la incorporación de la dignidad a los textos constitucionales y documentos internacionales sobre derechos humanos ha sido una constante, sobre todo, a partir de la Declaración Universal de los Derechos Humanos de 1948, encontrando su reflejo en buena parte de las constituciones posteriores a la segunda guerra mundial. Como es sabido, la constitución española se hace eco de la dignidad en su artículo 10.1: "La dignidad de la persona, los derechos inviolables que le son inherentes, el libre desarrollo de la personalidad, el respeto a la ley y a los derechos de los demás son fundamento del orden político y de la paz social», completándose ese reconocimiento con otras menciones expresas, como la del preámbulo ("Promover el progreso de la cultura y de la economía para asegurar a todos una digna calidad de vida»), o la del primer inciso del artículo 47 ( "Todos los españoles tienen derecho a disfrutar de una vivienda digna $y$ adecuada»). Sin embargo, el texto constitucional español no vuelve a mencionar expresamente la dignidad con ocasión del reconocimiento de los distintos derechos y libertades fundamentales en que ésta se proyecta.

Por su parte, la Constitución Nacional de la República Bolivariana de Venezuela de 1999, contiene una primera mención genérica a la dignidad en el párrafo primero de su artículo 3, relativo a los fines del Estado: "El Estado tiene como fines esenciales la defensa y el desarrollo de la persona y el respeto a su dignidad, el ejercicio democrático de la voluntad popular, la construcción de una sociedad justa y amante de la paz, la promoción de la prosperidad y bienestar del pueblo y la garantía del cumplimiento de los principios, derechos y deberes consagrados en esta Constitución". Esta referencia encuentra posterior concreción expresa en diversas ocasiones a lo largo del texto. Así, dentro del artículo 46, sobre el derecho al respeto de la integridad personal, el párrafo segundo establece que "Toda persona privada de libertad será tratada con el respeto debido a la dignidad inherente al ser humano". La dignidad también se encuentra explicitada en el primer párrafo del artículo 47 (en relación con los límites a la inviolabilidad del «hogar doméstico, el domicilio, 
derechos inherentes a la persona en razón de su dignidad, también constitucionalizados, adquieren la condición de derechos fundamentales e inviolables, puesto que sólo a través del ejercicio de los mismos es posible la vigencia, el mantenimiento y la incolumidad de aquélla, así como el libre desarrollo de la personalidad.

Dejando para más adelante (infra, apartado 3.1) un intento de aproximación a la nada fácil tarea de delimitar lo que haya de entenderse por "derechos de la personalidad", baste en este primer momento constatar la insuficiencia de la constitucionalización de los derechos (por muchos y elaborados mecanismos garantizadores de que ésta vaya acompañada) para que se pueda hablar de un real y efectivo cumplimiento de los mismos y, consecuentemente, de la dignidad humana en la que se fundamentan. Quizá por ello se ha podido escribir que "desde los inicios del constitucionalismo hasta hoy, esa imagen ilustrada del hombre, tal concepción integral de su dignidad, se encuentra en tensión con un acervo histórico que de modo recurrente ha sido instrumentalizado en su contra» (GuTIÉRREZ GutiÉRREZ, 2004: 339). Además, la realidad nos muestra diariamente un panorama que viene a contradecir las previsiones constitucionales. Comenzando por el derecho a la vida (y, a partir de él, continuando lógicamente por todos los demás), nadie que no pretenda engañarse a sí mismo puede congra-

y todo recinto privado de la persona"), así como en los artículos 55 (respeto de la dignidad y los derechos humanos por parte de los cuerpos de seguridad del Estado), 80 (respeto a la dignidad de los ancianos y ancianas por parte del Estado), 81 (ídem respecto de las personas con discapacidad o necesidades especiales), 91 (derecho a un salario que permita vivir con dignidad) y 332 (respeto de la dignidad y los derechos por los órganos de seguridad ciudadana). Manejamos la Guía Completa de la Constitución 1999 de la República Bolivariana de Venezuela, por Mago Bendahan (2000).

El reconocimiento de la dignidad está también presente en la Carta de los Derechos Fundamentales de la Unión Europea, incorporada como Parte II a la llamada "Constitución Europea» (más propiamente, Tratado por el que se establece una Constitución para Europa, firmado en Roma el 29 de octubre de 2004). Efectivamente, encontramos referencias a la misma en el Preámbulo de la Carta («[...] la Unión está fundada sobre los valores indivisibles y universales de la dignidad humana, la libertad, la igualdad y la solidaridad»), y en el artículo II-61 ("La dignidad humana es inviolable. Será respetada y protegida»), que a su vez abre el Título I de la Carta, bajo la rúbrica "Dignidad". Asimismo, el artículo I-2 del Tratado cita a la dignidad humana entre los valores en que la Unión se fundamenta. Como aproximación en clave crítica al Tratado y a la Carta, a las escasas perspectivas de eficacia real (e incluso de vigencia formal) de uno y otra, y a la medida en que ambos dan o no respuesta a los retos constitucionales que los originaron, véanse los trabajos de Alegre Martínez y Jimena Quesada (2005). 
tularse de que los derechos humanos son efectivamente respetados. La experiencia nos enseña que la dignidad "es atacada, despreciada, maltratada. Cada día. Cada hora. Cada minuto" (GonzÁlez PÉREZ, 2005: 17)4. Si esto ha sido así siempre, más claramente aún puede afirmarse en el momento actual, marcado, entre otros factores, por la omnipresencia de las nuevas tecnologías y, en concreto, de Internet. En efecto, si, como escribe PEGORARO (2004: 27), la realidad virtual (y lo mismo podría afirmarse, por ejemplo, en relación con la biotecnología) «transtorna las bases mismas del constitucionalismo, al menos por lo que se refiere al vasto sector de los derechos", cabría preguntarse, con el citado autor, si las constituciones nacionales representan a día de hoy una barrera suficiente para la protección de los mismos. Baste pensar de momento en los efectos deshumanizantes atribuibles a Internet, sobre los que ya ha empezado a alertar la doctrina (FERNÁNDEZ RoDRíGUEZ, 2004: 34-35), como la dependencia, o la tendencia al aislacionismo social ${ }^{5}$.

b) De la dignidad humana se deduce la existencia de un derecho al libre desenvolvimiento de la personalidad, que a su vez ha de considerarse como la matriz generadora de los derechos de la personalidad. Éstos son derechos del actuar de la persona, que, como ya hemos señalado, merecen y obtienen (en mayor o menor medida, y prescindiendo ahora de su eficacia real) reconocimiento y protección del mun-

4 Explica este autor que, «pese a su solemne sacralización en Declaraciones y Pactos internacionales, Constituciones y leyes de los Estados, la dignidad humana es objeto de continuos ataques incluso por parte de los propios Estados que firmaron aquellas declaraciones". Recuerda al respecto unas palabras de Juan Pablo II que, en su alocución de 22 de diciembre de 1979, observaba ya que «nunca se ha oído exaltar tanto la dignidad y el derecho del hombre a una vida hecha a medida del hombre, pero también nunca como hoy ha habido afrentas tan patentes a estas declaraciones".

${ }^{5}$ Al respecto, cita este autor algunas de las "sombras todavía sin disipar» que rodean a la Red de Redes: "banalización de la información (las enormes masas de información que circulan por la Red hacen primar el diseño, la forma y lo cuantitativo sobre el fondo y lo cualitativo); determinismo técnico; caos disfuncional; homogeinización (agresiva con el pluralismo cultural); dependencia (el enganchado o ‘hooked' es una psicopatología que requiere tratamiento específico); tendencia al aislacionismo social en cierto modo deshumanizante y que frisa la frontera de lo patológico (existen diversos estudios que inciden en esta línea, como uno de la Universidad Carnegie Mellon, que señala la correlación directa entre horas de Internet e incidencia de cuadros depresivos, u otro de la Universidad de Stanford, realizado por Norman NIE, que señala que los internautas más asiduos tienden a prescindir de amigos y familia)". 
do jurídico, en particular a través de su constitucionalización. De aquí podría inferirse (sin perjuicio de la ya mencionada necesidad de delimitación posterior más precisa) que todos los derechos que derivan de dicho desenvolvimiento libre (o que resultan imprescindibles para el mismo) son derechos de la personalidad. Y de aquí, a su vez, que los derechos de la personalidad son derechos de desenvolvimiento y, por ende, están íntimamente vinculados a la libertad (porque, sin ella, no hay desenvolvimiento posible) y a la integridad moral (porque cuando se afectan los derechos de la personalidad siempre se causa, al menos, un daño moral). Por eso, el reconocimiento y la protección constitucional de una y otra (libertad e integridad) aparecen como las exigencias mínimas, básicas e imprescindibles que deben acompañar a la constitucionalización de los derechos de la personalidad.

Centrándonos aquí fundamentalmente en el reconocimiento, resulta fácil percibir, tanto en constituciones latinoamericanas como en la española, y en la propia Constitución Europea, la presencia, junto con la dignidad humana como fundamento de los derechos de la personalidad según quedó dicho, del tándem libertad/integridad, como elementos necesarios para su eficacia, desarrollo, promoción e implementación ${ }^{6}$.

6 Tomando de nuevo como ejemplo de las primeras la Constitución venezolana de 1999, vemos cómo su artículo 46 establece que "toda persona tiene derecho a que se respete su integridad física, psíquica y moral», de lo cual se sigue, "en consecuencia», la prohibición de tratos crueles o degradantes, el derecho a la rehabilitación, el respeto debido a las personas privadas de libertad, el derecho de la persona a no ser sometida a experimentos científicos o a exámenes médicos sin su libre consentimiento, o las sanciones a funcionarios que infieran malos tratos o sufrimientos físicos o mentales a cualquier persona. Por su parte, el artículo 55 reconoce el derecho a la protección por el Estado "frente a situaciones que constituyan amenaza, vulnerabilidad o riesgo para la integridad física de las personas, sus propiedades, el disfrute de sus derechos y el cumplimiento de sus deberes", lo cual parece ir en el sentido indicado según el cual sin libertad no hay desenvolvimiento posible de los derechos. En cuanto a la libertad, es objeto de numerosas referencias a lo largo del articulado, en particular como principio fundamental en el Título I, y como derecho civil en el Capítulo III del Título III. El "desarrollo de la persona" aparece, como vimos, ligado al "respeto a su dignidad" en el artículo 3 (relativo a los "fines esenciales" del Estado). Y el vínculo entre libertad y desenvolvimiento de la personalidad, podemos encontrarlo en el artículo 20: «Toda persona tiene derecho al libre desenvolvimiento de su personalidad, sin más limitaciones que las que derivan del derecho de las demás y del orden público y social». Por último, en el artículo 89 se contempla el mandato dirigido al legislador de "mejorar las condiciones materiales, morales e intelectuales de los trabajadores". 
Quizá esta interacción se aprecia de manera especialmente clara e ilustrativa si se entra a analizar la importancia que la Constitución española reconoce al proceso educativo (SÁNCHEZ FERRIZ y JIMENA QUESADA, 1995; Cotino Hueso y SÁnchez FerRIZ, 2000; JimenA QueSAdA, 2005), como medio de interiorización de valores cuyo respeto resulta necesario para la convivencia en un clima de libertad, igualdad, solidaridad y tolerancia. En efecto, si el artículo 27.2 recoge, como objeto de la educación, "el pleno desarrollo de la personalidad humana en el respeto a los principios democráticos de convivencia y a los derechos y libertades fundamentales", salta a la vista la relación entre este precepto y el mencionado artículo 10.1 (que alude al "libre desarrollo de la personalidad" como uno de los postulados íntimamente vinculados a la propia dignidad humana, y que sirven para explicar, detallar y concretar el reconocimiento de ésta), y resulta fácil entonces encontrar la clave para comprender el modelo educativo constitucionalmente previsto: el desarrollo de la personalidad no puede ser pleno sin ser libre, y no puede ser libre sin ser pleno. Todo ello, además, en el marco del "Estado social y democrático de Derecho" (artículo 1.1). Igualmente, de ambos preceptos se deduce que, para lograr ese pleno/libre desarrollo de la personalidad, es necesario educar en el respeto a la dignidad propia $y$ ajena. Ello significa que, durante el proceso educativo, el alumno debe profundizar en esa característica inseparable de su persona. No es que vaya adquiriendo la dignidad según la vaya "aprehendiendo»

También en la Constitución española la libertad es contemplada en su dimensión de valor superior (artículo 1.1) posteriormente concretado como derecho en sus diversas facetas o vertientes (artículos 16 para la libertad religiosa, 17 para la libertad personal, 19 para la libre residencia y circulación, 20 para la libre expresión e información, etc.). En realidad, como se ha puesto de manifiesto (GARCía CuADRADO, 2002: 174), "todos los derechos y libertades del Título I y especialmente los derechos de libertad son concreción del valor superior libertad". (Vid., asimismo, SÁNCHEZ FERRIZ, 1995). Además, en el artículo 15 aparecen significativamente ligados los derechos de "todos" a "la vida y a la integridad física y moral, sin que, en ningún caso, puedan ser sometidos a tortura ni a penas o tratos inhumanos o degradantes".

La ya citada Constitución Europea, en su Parte II (Carta de los Derechos Fundamentales) recoge los distintos aspectos englobados en el Derecho a la integridad de la persona, en el artículo II-63 (compartiendo ubicación en el Título I, "Dignidad", con el derecho a la vida, la prohibición de la tortura y de las penas o los tratos inhumanos o degradantes, y con la prohibición de la esclavitud y del trabajo forzado). En cuanto a los derechos a la libertad y a la seguridad aparecen enunciados en el artículo II-66, dentro del Título II ("Libertades»). La dignidad y la libertad aparecen juntas en la enumeración —contenida en el Preámbulo de la Carta- de "valores indivisibles y universales" sobre los que está fundada la Unión, así como en el artículo l-2 del Tratado ("Valores de la Unión»). 
(pues ya le acompaña por su propia condición de persona), sino que va tomando conciencia de la misma, de sus implicaciones y consecuencias. Así entendido, dicho proceso estaría orientado a conseguir que el estudiante experimente, desde el principio de su formación, una noción vivencial de la dignidad, que en sucesivas etapas deberá concretarse en las nociones jurídicas de derechos humanos, y derechos y deberes fundamentales constitucionalmente reconocidos (ALEGRE MARTíneZ, 2003 b) ${ }^{7}$.

Similares impresiones (que nos serán de utilidad en momentos posteriores de nuestra reflexión) podemos extraer del artículo 102 de la Constitución venezolana, el cual (asimismo en el marco de un «Estado democrático y social de Derecho y de Justicia», a tenor del artículo 2) define la educación como un "derecho humano y un deber social fundamental", la califica de "democrática, gratuita y obligatoria" y de "servicio público", y la fundamenta "en el respeto a todas las corrientes del pensamiento, con la finalidad de desarrollar el potencial creativo de cada ser humano y el pleno ejercicio de su personalidad en una sociedad democrática basada en la valoración ética del trabajo y en la participación activa consciente y solidaria en los procesos de transformación social consustanciados con los valores de la identidad nacional, y con una visión latinoamericana y universalı ${ }^{8}$.

Pues bien: presentadas así las ideas básicas que centrarán nuestra atención, el siguiente paso deberá consistir en poner de manifiesto, como elemento común a ambas, la íntima relación entre los diversos

7 Por eso, en concreto respecto de los estudios de Derecho, acierta plenamente Oliver Araujo (2003: 26-27) cuando considera que la formación de buenos juristas es una "tarea compleja", pues no se trata sólo de proporcionar información sobre «muchas leyes» (sujetas, por lo demás, a continuos cambios), sino, sobre todo, de que el alumno adquiera durante la Licenciatura el espíritu crítico y la necesaria sensibilidad para plantearse los problemas jurídicos en términos que vayan más allá del mero juicio técnico. Se requiere, por tanto, una "formación integral», que englobe «no sólo una alta preparación técnica e intelectual, sino también un amplio conocimiento de los valores e intereses profundamente humanos". En definitiva: se impone la necesidad de que en nuestras Facultades se formen "hombres cultos", para que el Derecho «continúe siendo ciencia al servicio de la justicia y no de la política o de la ideología».

8 Por su parte, el Tratado por el que se establece una Constitución para Europa, que según se indicó incorpora como Parte II la Carta de los Derechos Fundamentales de la Unión Europea, recoge el derecho a la educación en el artículo II-74, sin que se ponga de manifiesto ese vínculo existente con el libre desarrollo de la personalidad; aun así, el precepto aparece ubicado en el Título II, bajo la rúbrica "Libertades". 
elementos a cuya constitucionalización nos venimos refiriendo (dignidad, integridad física y moral, derechos de la personalidad, libre desarrollo de la misma). Y en este sentido, si tuviéramos que extraer el denominador común o determinar el hilo conductor que está detrás del hecho de que todos ellos aparezcan estrechamente unidos y constitucionalmente vinculados, sin duda lo encontraríamos, no sólo en el ya mencionado carácter fundamental y fundamentador de la dignidad (Alegre Martínez, 1996: 42 y 66), sino también, y como consecuencia del mismo, en el afán constitucional por proteger la individualidad de la persona.

\section{LA INDIVIDUALIDAD CONSTITUCIONALIZADA Y SU FUNDAMENTO EN LA DIGNIDAD DE LA PERSONA}

\subsection{Perfil y dimensiones de la individualidad}

Tal y como acabamos de adelantar, la especial vinculación con la persona, con el individuo, es el nexo que une a una serie de derechos y libertades: los Ilamados derechos de la personalidad. Las constituciones, al reconocerlos y hacerse eco de ellos, están intentando proteger una serie de bienes jurídicos inherentes a la personalidad o, dicho de otro modo, a la individualidad de la persona. De hecho, tales bienes jurídicos, como la vida, la integridad, el honor, la intimidad, la imagen, tienen el común el estar referidos «a la dimensión o al ámbito más privado o íntimo de la persona», siendo "del todo indispensables para el desenvolvimiento personal y social de aquélla, sin cuyo disfrute y goce no es posible vivir en condiciones mínimamente tolerables" (Cfr. BusTOS PUECHE, 1997: 23) ${ }^{9}$. Y es justamente esa estrecha interconexión la que permite reconducirlos a uno solo: la individualidad ${ }^{10}$.

9 En opinión del autor citado, que mantiene al respecto un criterio estricto, "son bienes de la personalidad: de carácter o naturaleza corporal o físico, vida e integridad física; y de naturaleza moral o incorporal, honor e intimidad, en la que va incluida la imagen que, en rigor, es una manifestación de la intimidad».

10 La «individualidad» es definida por el Diccionario de la Lengua Española (REAL ACADEMIA ESPAÑOLA, 1984) como la "calidad particular de una persona o cosa por la cual se da a conocer o se señala singularmente». Esta definición se ve enriquecida al ponerla en relación con las de términos más o menos equivalentes. Así, se entiende por "singularidad" la "particularidad, distinción o separación de lo común». Y por "idiosincrasia», la "índole del temperamento y carácter de cada individuo, por la cual se distingue de los demás». LuCAS MURILLO DE LA CUEVA (1991: 7778), afirma, respecto de la cuestión de si el artículo 18.1 de la Constitución española 
La clara conexión entre estos bienes y derechos, y la dignidad humana en la que encuentran su fundamento ha sido puesta de manifiesto por el Tribunal Constitucional español, por ejemplo, en su sentencia 231/1988 de 2 de diciembre. Después de afirmar acertadamente en su fundamento jurídico 3 que los derechos reconocidos en el artículo 18 de la Constitución vienen "derivados sin duda de la 'dignidad de la persona' que reconoce el artículo 10 de la CE», añade que tales derechos «implican la existencia de un ámbito propio y reservado frente a la propia acción y conocimiento de los demás, necesario — según las pautas de nuestra cultura - para mantener una calidad mínima de la vida humana» ${ }^{11}$.

En definitiva, lo que la dignidad aporta a través de su carácter fundamentador es, en palabras de MARINA y DE LA VÁLgOMA (2000: 227, 253 ss., 261 ss.) "un gancho trascendental del que colgar todos los derechos y deberes", en cuanto que "de su reconocimiento y del reconocimiento de los derechos iguales e inalienables dependen la libertad, la justicia y la paz»: en ella encontramos "el fundamento de una nueva manera de vivir», un "valor absoluto" que la persona tiene por el hecho de serlo, y que viene a consistir en la «capacidad de afirmarnos como seres valiosos". El reconocimiento de la dignidad supone un progreso ético, porque se presenta asociada a la posesión de derechos y al deber de respetar los derechos de los demás: "funda los derechos porque es previamente postulado por nuestro afán de vivir con derechos" (ibídem: 268, 27); los cuales, además, reciben de la dignidad su carácter universal: "si los derechos derivan de la dignidad humana, y ésta es común a todos los seres humanos, los derechos dimanantes de tal dignidad han de ser también comunes" (MARTíneZ-PuJALTE, 1995: 136).

Bien puede afirmarse, entonces, que "la presencia de la idea de la dignidad de la persona como valor constitucional, no sólo centra la pluralidad abierta de 'valores superiores', sino que aparece como criterio integrador y unificador del sistema de los derechos fundamentales" (GARCía García, 2003: 39). Y todo ello, al servicio de la personalidad, con-

( Se garantiza el derecho al honor, a la intimidad personal y familiar y a la propia imagen») contiene uno o varios derechos, que ésta se plantea "por la identidad material del objeto que cada uno de esos términos expresan. En otras palabras, por ser formas diferentes de proteger a la propia persona, en sí misma considerada. En último extremo su dignidad e individualidad irrepetible»

11 A esta idea vuelve a referirse el Tribunal Constitucional, en relación con la intimidad familiar, en la STC 197/1991, de 17 de octubre. La vinculación entre estos derechos y la dignidad de la persona vuelve a ser recordada por el Tribunal Constitucional, entre otras, en la sentencia 99/1994 de 11 de abril, fundamento jurídico 5. 
siderada como "centro de imputación» de múltiples derechos e intereses, encaminados a garantizar su libre desarrollo, así como "la interdicción de instrumentalizar al hombre» (GUTIÉRREZ GUTIÉRREZ, 2004: 336 y ss., 341) ${ }^{12}$.

La conexión entre dignidad y personalidad, por tanto, viene a recordarnos, ni más ni menos, que la persona no es un objeto, sino «un fin en sí mismo, y nunca podrá ser usado como medio al servicio de terceros sin sacrificar su dignidad" (FeRnÁndeZ de Alarcón MedinA, 2005: 12). Para cualquiera de las numerosas situaciones a las que esta afirmación puede resultar aplicable (por ejemplo, en relación con el derecho a la vida del no nacido, clonación con fines terapéuticos o reproductivos, experimentación con células madre embrionarias, manipulación o selección de embriones, etc.), será necesario insistir, con el mismo autor, en que "la dignidad humana es inviolable, y no pertenece al orden del hacer, del poder o del saber. Pertenece al ser. Se es digno de la más escrupulosa protección por el hecho de ser humano". En la dignidad humana, radica la necesidad ineludible de proteger la individualidad de la persona ${ }^{13}$.

12 Al respecto podemos citar, con este último autor, la Sentencia 192/2003 de 27 de octubre, del Tribunal Constitucional español, en cuyo fundamento jurídico 7, en relación con el tiempo de descanso, se refiere a "la dignidad personal del trabajador, entendida ésta como el derecho de todas las personas a un trato que no contradiga su condición de ser racional igual y libre, capaz de determinar su conducta en relación consigo mismo y su entorno [...]". De tal modo que, constituyendo la dignidad "un minimum invulnerable que todo estatuto jurídico debe asegurar», "la concepción del período anual de vacaciones como tiempo cuyo sentido único o principal es la reposición de energías para la reanudación de la prestación laboral supone reducir la persona del trabajador a un mero factor de producción y negar, en la misma medida, su libertad, durante aquel período, para desplegar la propia personalidad del modo que estime más conveniente. Una tal concepción, según la cual el tiempo libre se considera tiempo vinculado y la persona se devalúa a mera fuerza de trabajo, resulta incompatible con los principios constitucionales que enuncia el artículo 10.1 CE (dignidad de la persona y libre desarrollo de su personalidad), a cuya luz ha de interpretarse, inexcusablemente, cualquier norma de Derecho [...]".

${ }^{13}$ Es sabido que la Constitución española ubica la dignidad en el artículo 10.1, como pórtico del Título l, pero sin estar integrado en ninguno de sus capítulos. Eso significa que, al menos desde el punto de vista de sus garantías (recurso de amparo ex artículo 53.2), "es claro que [...] no existe un 'derecho fundamental a la dignidad o al respeto a la dignidad de la persona'» (RuIz MIGUEL, 1995 c: 111-112).

Es obligado citar al respecto, como hace este autor, la sentencia 120/1990 de 27 de junio, del Tribunal Constitucional, en cuyo fundamento jurídico 4 puede leerse: "Sólo en la medida en que tales derechos sean tutelables en amparo y únicamente con el fin de comprobar si se han respetado las exigencias que, no en abstracto, 
Pues bien: precisamente por el hecho de aglutinar diversos bienes jurídicos cristalizados en los diversos derechos y libertades constitucionalmente reconocidos, fundamentados en la dignidad humana, y por

sino en el concreto ámbito de cada uno de aquellos deriven de la dignidad de la persona, habrá de ser ésta tomada en consideración por este Tribunal como referente. No, en cambio, de modo autónomo para estimar o desestimar las pretensiones de amparo que ante él se deduzcan". Similar argumentación encontramos en las sentencias 64/1986 de 21 de mayo y 184/1990 de 15 de noviembre, así como en varios autos, como el 95/1982 de 17 de febrero o el 371/1982 de 24 de noviembre.

Ello no excluye que la dignidad haya sido utilizada expresamente por el Tribunal en la fundamentación de algunas sentencias de amparo, junto con los derechos fundamentales directamente implicados. Así en la sentencia 214/1991 de 11 de noviembre (caso Violeta Friedman / Leon Degrelle), fundamento jurídico 8, podemos leer que las libertades ideológica y de expresión (arts. 16 y $20.1 \mathrm{CE}$ ), «no garantizan [...] el derecho a expresar y difundir un determinado entendimiento de la historia o concepción del mundo con el deliberado ánimo de menospreciar y discriminar, [...] pues sería tanto como admitir que, por el mero hecho de efectuarse al hilo de un discurso más o menos histórico, la Constitución permite la violación de uno de los valores superiores del ordenamiento jurídico, como es la igualdad (art. 1.1 CE) y uno de los fundamentos del orden político y de la paz social: la dignidad de la persona (art. 10.1 CE)". Lo que lleva al Tribunal a concluir que "procede declarar la existencia, en el presente caso, de intromisión ilegítima en el honor y dignidad de la hoy recurrente, de conformidad con lo dispuesto en los artículos 1.1, 10.1 y 18.1 CE»

Esta no consideración de la dignidad humana en sí misma como derecho fundamental en la Constitución española, contrasta con lo que sucede en la alemana: su artículo 1, que abre el Capítulo primero, "De los Derechos Fundamentales» (Die Grundrechte) califica la dignidad como «intangible» (unanntasbar); mientras que el artículo 2.1 establece que "Todos tienen derecho al libre desenvolvimiento de su personalidad siempre que no vulneren los derechos de otro ni atenten al orden constitucional o a la ley moral» ("Jeder hat das Recht auf die freie Entfaltung seiner Persönlichkeit, soweit er nicht die Rechte anderer verletzt und nicht gegen die verfassungsmäßige Ordnung oder das Sittengesetz verstößt»). Es de destacar en este precepto la referencia a la "ley moral», equiparándola al "orden constitucional" en cuanto a la posibilidad de que su infracción motive la interrupción del derecho al libre desarrollo de la personalidad. Se diferencia aquí el libre desarrollo de la personalidad (que cede en caso de la vulneración por el sujeto de derechos ajenos) de la dignidad, que es «intangible» (Cfr. Alegre Martínez, 1996: 35, 36 y la bibliografía allí citada).

Respecto de lo que en este punto nos interesa de manera específica, en la doctrina española reciente, GUTIÉRREZ GuTIÉRREZ (2004: 331, 336, 338-339) se refiere al hecho de que la dignidad quede excluida del recurso de amparo y de la protección que supone el procedimiento agravado de reforma (a la vista de la letra del artículo 168), señalando que "en España, al no ser la dignidad de la persona un derecho fundamental, el sujeto queda irremisiblemente fragmentado como eventual centro de imputación de múltiples derechos singulares, sin que desde ellos quepa recomponer su esencial integridad. El hecho de que la dignidad no opere como derecho funda- 
el hecho de servir de denominador común a los principios y valores a los que nos venimos refiriendo, la individualidad es un concepto sumamente rico, lleno de contenido, cuyo perfil puede ser contemplado a través de diversas dimensiones o notas características. Desde nuestro punto de vista, éstas serían, al menos, las siguientes:

- La personalidad o humanidad: términos tomados aquí en su más amplio sentido: condición de persona, de ser humano, e indisociablemente unidos a la racionalidad, sociabilidad y la privacidad (comprensiva, a su vez, de la intimidad) ${ }^{14}$.

mental determina que tampoco en los derechos fundamentales particulares se busque sistemáticamente su contenido de dignidad. No se trata, pues, de una dignidad humillada o herida, de las lesiones a la dignidad constitucionalmente reconocida que infringen, pero no niegan el orden constitucional; sino, más radicalmente, de la dignidad menguada, de la deficiente forma en que la dignidad es recogida por nuestra Constitución. Una dignidad menguada que es también, y precisamente por ello, dignidad quebrada». Por lo demás, añade este autor (p. 342) que "la vieja doctrina nacional de los derechos ha sido definitivamente descontextualizada: éstos no se vinculan ya a la participación de su titular en comunidad alguna, sino que resultan progresivamente fragmentados y diferenciados en los procesos de globalización".

Por nuestra parte, consideramos que la otra cara este planteamiento, que es en buena medida compartible, la podemos encontrar en la suprema eficacia normativa que corresponde a la dignidad, por el hecho de su incorporación a la Constitución, y por el papel que desempeña dentro de la misma, lo cual debe quedar afirmado independientemente de las concretas garantías que le puedan corresponder de acuerdo con su ubicación sistemática (al respecto, Alegre MARTínez, 1996: 117 ss.; 2005: 48-49). Al menos respecto de los derechos de la personalidad que aquí nos ocupan, su fundamento común en la dignidad contribuye precisamente a "recomponer» la "esencial integridad" de la persona.

${ }^{14}$ Como nos recuerda Fernández Rodríguez (2004: 67-68), la doctrina española suele distinguir (si bien de modo no unánime) entre intimidad y privacidad (derivada ésta de la voz inglesa privacy), "concibiendo ésta como más amplia que aquélla al aludir a datos no íntimos pero que la persona quiere que no sean difundidos". Ésta parece ser la línea seguida por el legislador español, que en la exposición de motivos de la ya derogada Ley Orgánica 5/1992 de 29 de octubre (sustituida por la Ley Orgánica 15/1999 de 13 de diciembre, de protección de datos de carácter personal), distinguía entre la intimidad, que «protege la esfera en que se desarrollan las facetas más singularmente reservadas de la vida de la persona", y la privacidad, la cual "constituye un conjunto más amplio, más global, de facetas de su personalidad que, aisladamente consideradas, pueden carecer de significación intrínseca pero que, coherentemente enlazadas entre sí, arrojan como precipitado un retrato de la personalidad del individuo que éste tiene derecho a mantener reservado". No faltan, sin embargo autores que proponen un concepto más amplio de intimidad (RuIz 
- La irrepetibilidad, aspecto de especial importancia en un contexto como el actual, en el que, merced, entre otros factores, a los avances de la biomedicina, la idea de progreso parece ir unida a la relativización o devaluación del respeto a la vida, a la dignidad y a los derechos de los demás, mientras nos vamos convirtiendo en testigos impasibles a los que ya nada parece extrañar ni sorprender. Y (retomando las anteriores consideraciones sobre la importancia del proceso educativo) esto será lo que suceda con quienes hoy se forman en nuestras aulas, si en ellas no se reflexiona seriamente sobre las consecuencias de aceptar sin más las modificaciones normativas y los ya aludidos avances científicos y técnicos, prescindiendo en unas y otros de la dimensión ética. Así, por ejemplo, nuestros niños y jóvenes aceptarán sin discusión que el fin justifica los medios; que unas vidas merecen ser vividas y otras no; que unas personas pueden - e incluso deben- decidir sobre la vida de otras; que, después de todo, la persona no es más que un conjunto de células, órganos, huesos y carne: un mero instrumento, un objeto, un trozo de materia orgánica; y que por eso, al fin y al cabo, no existe una gran diferencia entre una persona y -por ejemplo- una oveja (cfr. Alegre MARTínez, 2002 a, y 2003 b: 8). Como recientemente se ha escrito, "una postura exigente y rigurosa que reclame la protección de la vida humana — desde su concepción hasta su final-sigue siendo una apuesta por el hombre que entronca con los mejores fundamentos del reconocimiento de sus derechos" (NOMBELA, 2005: 3$)^{15}$. Por las razones que venimos indicando, no concebimos un

Miguel, 1995 b: 3209-3210, cit. por Fernández Rodríguez, 2004: 67, y Ruiz Miguel: 1995 a: 29-30). Este último autor, aceptando la posibilidad de considerar que "lo privado sería un ámbito que, abarcando lo íntimo, lo supera", admite que "podría hablarse de intimidad en sentido amplio como lo comprensivo también de lo privado" (p. 29); lo que le lleva a concluir que "no hay una regla fija al respecto y el sentido del concepto dependerá de las circunstancias". Por su parte, el Tribunal Constitucional, en su auto 221/1990 de 31 de mayo, fundamento jurídico 3, señala que "el derecho fundamental a la intimidad excluye las intromisiones de los demás en la esfera de la vida personal y familiar de los ciudadanos").

${ }_{15}$ Tal y como pone de manifiesto este autor, «es innegable que el mensaje cristiano, fundamento de las raíces bimilenarias de nuestra cultura, supuso un hito en el reconocimiento de la dignidad humana, base de sus derechos y fundamento del respeto a su libertad y autonomía». Por tanto, no estará de más recordar con él que Juan Pablo II, "superviviente de los peores totalitarismos», e «intérprete excepcional de este mensaje», señaló que, si bien "la búsqueda de la verdad científica, con los métodos propios de la investigación, es un imperativo para la inteligencia humana", no es menos cierto que, al representar la persona un valor, sólo desde un sistema de principios bien asentados podremos abordar la valoración ética de las posibilidades de intervención sobre la vida humana que se nos abren». Sobre la aportación de la 
"mejor fundamento" para los derechos que la dignidad humana; la cual (en palabras de LANDA ARROYo, 2002) "muestra todas sus posibilidades comprensivas y transformadoras o sus dificultades ordenadoras, cuando afirma sus raíces frente a los dilemas concretos que se presentan con relación a [...] los novísimos desafíos del derecho genético».

- La igualdad y la universalidad como presupuestos necesarios para que esa individualidad sea en todo caso respetada, a través de los derechos que son exigencias de la misma. En efecto, ni la dignidad ni los derechos inviolables en que ésta se proyecta existen sólo existe allí donde el Derecho los reconoce: si consideramos que la posesión de derechos se funda en la persona para evitar así la arbitrariedad, y en la universalidad como solución más segura frente a los peligros de toda discriminación (MARINA y DE LA VÁLGOMA, 2000: 199), habrá que coincidir con MARTínEZ-PUJALTE (1995: 144-145) en que la universalidad significa que todos los seres humanos son titulares de los derechos, independientemente de que la comunidad política de que forman parte se los reconozca o no: "en caso de que no lo haga, ello no significa que los ciudadanos de esa comunidad o país no tengan derechos humanos, sino que, precisamente, porque los tienen, ese régimen político y jurídico debe ser calificado como injusto, y puede cuestionarse la validez de sus normas".

- La integridad, constitucionalizada, según sabemos, en sus distintas vertientes (física, psíquica, moral) y que, conjuntamente con la libertad, nos pone sobre la buena pista a la hora de verificar una de las hipótesis básicas presentadas en el apartado anterior: la vulneración de un derecho de la personalidad provoca necesariamente, al menos, daños morales, pues afecta a la integridad del ser humano. Y ello porque ésta incluiría, a su vez, la incolumidad, la intangibilidad, al derecho a no ser maltratado, a no ser molestado, a no ser violentado, a no ser obstruido en su desenvolvimiento. La integridad, fundamentada en la dignidad humana, se configura, así, como una derivación del libre desarrollo de la personalidad, y éste como una concreción de la libertad.

No se trata aquí únicamente del derecho a estar solo, a no ser molestado (CARRILLO, 2003), a disfrutar de un ámbito de intimidad e incluso,

Iglesia católica al concepto de dignidad humana, puede verse también ALEGRE MARTíNEZ (1996: 22-25). La preocupación por la dignidad humana es constante en las encíclicas de JUAN PABLo II. Baste citar la Sollicitudo rei socialis (30 de diciembre de 1987), los apartados 13, 53 y 61 de la Centesimus annus ( 1 de mayo de 1991) o, destacadamente, Evangelium Vitae (25 de marzo de 1995), "sobre el valor y el carácter inviolable de la vida humana». 
si se quiere, de privacidad, como veíamos más arriba ${ }^{16}$. Hablamos en este punto de un derecho al desarrollo del propio yo: de un derecho a ser lo que se es, en expresión usada por SPINOZA en su Tractatus para definir, precisamente, la libertad.

\subsection{La individualidad y el paulatino reconocimiento de los derechos}

La posibilidad de detectar ese conjunto de manifestaciones o vertientes que permiten afirmar el carácter poliédrico de la individualidad, es fruto de un largo proceso de conciencia cada vez más exigente de esa individualidad y de los derechos y libertades de la persona. Lo mismo que se ha afirmado, por ejemplo, respecto de la idea de justicia, puede señalarse también a propósito de esa exigencia creciente en relación con la individualidad: se trata de una especie de "dinamismo reivindicativo", de una "ampliación continua» de la idea, una "dialéctica creadora que rompe la estabilidad y la repara a un nivel más alto"; en definitiva, un proceso que se ha movido por impulsos que «rompen el equilibrio y lo reajustan después" (Cfr. MARINA y DE LA VÁlgOMA, 2000: $24,48)$. Para verificar esta premisa, bastará sencillamente con atender a dos datos, que a su vez suscitan algunas consideraciones adicionales:

a) En primer lugar, el hecho de que los derechos y libertades que ahora encontramos proclamados en las actuales constituciones y declaraciones internacionales de derechos, no se han reconocido todos a la vez, sino que su aparición y plasmación en dichos textos es fruto de un proceso evolutivo que comprende varias etapas, en cada una de las cuales se va poniendo el acento en la tutela y protección de nuevas aspiraciones y necesidades que van surgiendo, y que se van planteando una vez logradas y satisfechas (en mayor o menor medida) las anteriores. Esta es justamente la idea que late en lo que se ha dado en Ila-

16 Señala CARRILlo (2003: 15) que «El derecho a no ser molestado o el derecho a estar solo (to be let alone) es una expresión que ha hecho fortuna para describir el derecho de la persona a proteger su vida privada y su intimidad». En opinión de este autor, si bien mantiene su validez el planteamiento liberal clásico que considera el derecho a la intimidad como aquél que «habilita a su titular para rechazar cualquier intromisión sobre aquel ámbito de su vida privada que es inaccesible a los demás si no es bajo su explícito consentimiento", la lectura de los textos constitucionales recientes nos lleva a percibir que «el derecho a la intimidad como derecho fundamental de la personalidad es algo más que el derecho a no verse perturbado". En efecto, la garantía de este derecho "no sólo es el poder de resistencia a una intromisión ilegítima, sino también la potestad de controlar el flujo de información que pueda circular en el escenario público". 
mar las generaciones de derechos: "la aplicación del criterio cronológico [para clasificarlos] ha conducido a la agrupación de los derechos según las diferentes etapas generacionales en que ha ido sintiéndose su necesidad y en que, consecuentemente, han sido proclamados. Así, se habla con frecuencia de los 'derechos de la primera generación' (para designar a los derechos civiles y políticos), de los 'derechos de segunda generación' (para referirse a los derechos económicos, sociales y culturales), de 'derechos de la tercera generación' (para identificar a los llamados también 'derechos de solidaridad') y de 'derechos de la cuarta generación' (para aludir a los derechos de la era informática y biotecnológica)" (DE CASTRO CID, 2003: 246).

Claro que, como indica a continuación el mismo autor «este criterio, que es con toda evidencia, el más puramente descriptivo, parece tener muy poca utilidad para el conocimiento teórico de los derechos, ya que no aporta a la explicación de los mismos más que una simple connotación extrínseca: el momento histórico en que se produce su incorporación a los catálogos de las correspondientes declaraciones». Por eso, resultan necesarias algunas visiones complementarias, que, junto con la clasificación expuesta, se enriquecen mutuamente y amplían nuestra perspectiva, permitiendo al mismo tiempo comprobar la hipótesis de la creciente conciencia de la individualidad:

- Así, manteniendo como premisa válida la clasificación de derechos por "generaciones", podríamos tomar como referencia para la misma, más allá del mero hecho cronológico, algún criterio que tuviera más que ver con los diferentes estadios evolutivos en el reconocimiento de los derechos como atributos de la persona, en función de la consideración de que es objeto ésta en cada uno de aquéllos ${ }^{17}$.

En este sentido, hablaríamos (MAGo BENDAHÁN, 1998: 48-62) de derechos de primera generación para referirnos a aquellos que son originarios, generativos, inherentes al ser humano contemplado como individuo (y que tendrían que ver con lo que se viene denominando derechos de la personalidad). Junto a ellos, tendríamos los de segunda generación, como derechos derivativos, derechos del hombre en sociedad, igualmente constitucionalizados, algunos de los cuales también podrían encajar en una acepción amplia de los derechos de la personalidad (derechos al trabajo, a la vivienda, a la libre circulación, a la protección de la familia, a vivir en democracia, etc.). En la tercera generación se agruparían derechos descubiertos más recientemente:

17 Sobre el debate doctrinal en torno a la clasificación de los derechos humanos en "generaciones", véase ROdRíGUez PALOP (2002: 78 y ss.). 
aquellos que siempre estuvieron ahí, pero sólo han podido aflorar al amparo de los avances científicos y socio-culturales, y de las consiguientes nuevas reflexiones sobre el destino de la humanidad, que en buena medida habrá de depender del respeto hacia los mismos: serían los llamados derechos transgeneracionales o de las generaciones futuras, (aunque también podrían denominarse derechos altruistas o derechos de dimensión internacional) y entre ellos se encontrarían los relativos a la supervivencia del planeta y sus especies (derechos relacionados con el medio ambiente, derechos ecológicos). Por último, la cuarta generación aglutinaría algo más que derechos, y estaría más bien centrada en los objetos de protección. Así, por ejemplo, lo atinente a especies no humanas, pero a las que la humanidad tiene el derecho (y la obligación) de defender, proteger y querer. Se trataría, efectivamente, de los derechos de los animales, desde la nueva perspectiva de su consideración paralela a la sensibilidad del ser humano, siendo más bien un derecho humano que se proyectaría sobre los animales. También podríamos considerar aquí incluidos los derechos de vecindad o derechos societarios, entendiendo por tales aquellos que nos corresponden a todos, sin que pueda individualizarse el titular, y que se ubicarían más allá de la hoy anacrónica distinción entre derecho público y derecho privado, tendiendo sus mecanismos protectores a alejarse de la coacción para acercarse más a la conciliación, por ejemplo, a través de mecanismos como la Justicia de Paz (MAgo Bendahán, 1995) ${ }^{18}$.

- El horizonte se amplía aún notablemente si tomamos además en consideración la figura de los derechos innominados y la consiguiente posibilidad de invocarlos legalmente, de cara a proteger al individuo frente a las nuevas formas de agresión susceptibles de generarle sufrimiento, todo ello con la debida y necesaria cobertura constitucional a pesar de no estar esos nuevos derechos taxativamente previstos en la

18 En suma, como ha señalado RODRíGUEZ PALOP (2002: 36), "la expresión 'tercera generación de derechos humanos' que puede conectarse con la terminología 'cuarta generación de derechos humanos', supone adoptar, en su análisis, una perspectiva histórica y racional. Esta apelación a la historia implica concebir que el catálogo de los derechos no es una obra acabada sino que está abierta a nuevas necesidades y demandas sobre cuya satisfacción puede existir un amplio consenso en un contexto determinado". Por eso, considera esta misma autora (ibídem, p. 87) que "de acuerdo con una determinada concepción de los derechos, puede mantenerse una visión histórica de los mismos y elaborar un catálogo abierto a las nuevas exigencias sin que esto implique necesariamente incluir en su seno a todas ellas a discreción. Se trata de establecer criterios a partir de los cuales sea posible apartar las necesidades que merecen ser satisfechas de aquellas otras que por su escasa importancia no pueden ser el fundamento de nuevos derechos humanos". 
Norma Básica. Desde esta perspectiva, además, la protección jurídica no se limitaría a los derechos y deberes, sino que se extendería también a los intereses, a las costumbres, a los valores socio-culturales, a los sentimientos, conectando así con la idea de daño moral. Obsérvese, al respecto, lo establecido en el artículo 22 de la Constitución venezolana de 1999: "La enunciación de los derechos y garantías contenidos en esta Constitución y en los instrumentos internacionales sobre derechos humanos no debe entenderse como negación de otros que, siendo inherentes a la persona, no figuren expresamente en ellos. La falta de ley reglamentaria de estos derechos no menoscaba el ejercicio de los mismos". Esta idea podría y debería entenderse al servicio de una concepción integral de la protección de la persona (también, por tanto, de sus intereses y sentimientos), más allá de la mera protección de los derechos ${ }^{19}$.

19 Ejemplos en esta línea, necesitados sobre todo de profundización en la práctica, podríamos encontrarlos en el frecuentemente llamado derecho a no emigrar, "es decir, a vivir en paz y dignidad en la propia patria (JUAN PABLO II, 2004: 5), o en el cada vez más insistentemente proclamado derecho a la alimentación suficiente $y$ adecuada (presente ya en el artículo 25 de la Declaración Universal de los Derechos Humanos de 10 de diciembre de 1948, así como en el artículo 11 del Pacto Internacional de Derechos Económicos, Sociales y Culturales de 19 de diciembre de 1966, y en relación con el cual la Organización de las Naciones Unidas ha declarado, entre otros, el objetivo de hambre cero para el año 2015).

Para una delimitación terminológica y clarificación conceptual en torno a expresiones como "derechos ecológicos", "derechos de la sociedad tecnológica", "derechos de la solidaridad" y "derechos humanos de tercera o cuarta generación", todo ello en el marco de lo que se viene denominando "nuevos derechos", puede verse RODRíGUEZ PALOP (2002), especialmente pp. 27 y ss.

Respecto de ese calificativo de "nuevos» derechos, REVENGA SÁNCHEZ (2002: 107108) ha señalado que "puede resultar más o menos comprensible según cuál sea la cultura constitucional de referencia». Así, "Una acostumbrada a la abstracción en el modo de entender la Declaración de derechos, y familiarizada con el protagonismo del juez a la hora de actualizarla y dotarla de significado, parece poco proclive a hacer del factor novedad un tópico determinante dentro del sistema general de los derechos". En este caso, "el sistema de derechos resulta plenamente acomodaticio a transformaciones de ida y vuelta; tiene el grado de elasticidad que admite el ingreso del derecho nuevo, pero no excluye reconsideraciones del mismo que puedan neutralizar su alcance o hacerlo desaparecer». Por el contrario, "una tradición constitucional hecha de quebrantamientos y reconstrucciones, una cultura consciente de (y orientada hacia) el peso determinante de la codificación de los derechos al máximo nivel, sí tiene en los derechos nuevos un factor que perturba considerablemente su lógica interna». En este supuesto, "la afirmación del derecho nuevo, su yuxtaposición al catálogo de los derechos establecidos, confiere a aquél una resistencia y un carácter inflexible que plantea las más crudas incógnitas sobre el lugar 
- Además, para una cabal comprensión de la sucesiva aparición de generaciones de derechos y libertades, consideramos que este dato debe contemplarse sin perder de vista la idea de indivisibilidad de los derechos, así como la ya mencionada de universalidad, en cuanto que ambos principios, de alguna manera, vienen a matizar dicho fenómeno de cara a evitar visiones parciales o conclusiones reduccionistas.

Respecto del principio de indivisibilidad, responde a la idea de que "los derechos humanos constituyen un todo", en el que "no cabe la aceptación parcial»: no pueden, pues, dividirse (SÁNCHEZ FERRIZ y JIMENA QuesADA, 1995: 40). Como nos recuerda JIMENA QuesadA (2004: 143, 182 ), ha sido proclamado a nivel universal en el apartado I.5 de la Declaración final de 25 de junio de 1993, que ponía fin a la Conferencia Mundial sobre Derechos Humanos celebrada en Viena. Allí se pone de manifiesto que "los derechos humanos son universales, indivisibles, interdependientes y están relacionados entre sí. La comunidad internacional debe tratar los derechos humanos en forma global y de manera justa y equitativa, en pie de igualdad y dándoles a todos el mismo peso". En palabras del autor citado, este principio debe conducir a la afirmación de «la igual importancia de los derechos sociales respecto de las demás categorías de derechos" y a catalogar "como inexistentes las paredes divisorias insalvables" ${ }^{20}$.

de la Constitución y el peso que corresponde, en el conjunto del sistema político, a cada uno de los intérpretes de ella».

${ }^{20}$ Recuerda JiMENA QUESADA $(2004: 143,144)$ que este principio está en el origen del hecho de que la Declaración Universal de 1948 contuviera tanto derechos cívicopolíticos como socio-económicos, así como el que, con fecha 19 de diciembre de 1966, "se adoptaran los dos Pactos relativos a ambos tipos de derechos, por más que el sistema de tutela creado por el Pacto de derechos civiles y políticos revestía un carácter cuasi-judicial (el Comité de derechos humanos) mientras el mecanismo de control establecido en el Pacto de derechos económicos, sociales y culturales se reconducía a la presentación de informes estatales.

Un contraste similar se observa a nivel europeo, donde, siguiendo al mismo autor (ibídem, 140-141), observamos que "la Carta Social Europea de 1961 continúa colocada en una posición secundaria, tanto en el ámbito del Consejo de Europa, como en el marco de la Unión Europea. En lo que concierne al primero, diversas razones han hecho acreedora, desafortunadamente, a la Carta de Turín del calificativo 'hermana pobre' del Convenio de Roma de 1950 [de Protección de los Derechos Humanos y de las Libertades Fundamentales], entre ellas: de entrada, la tardanza en la aprobación de la Carta (1961), que quedaba postergada en relación con la pronta adopción del Convenio (1950) [...]; y, a continuación, el débil mecanismo de control, sustentado en informes, de la Carta Social de 1961 en comparación con el sistema judicial instituido en el Convenio Europeo de 1950 articulado a través del Tribunal Europeo de Derechos Humanos». Y en lo referente a la Unión Europea, la Carta de 
En cuanto a la universalidad, de ella se ha dicho (PECES-BARBA MARTíNEZ, 2004: 191 y ss.) que alude "al menos a tres cosas diferentes, aunque vinculadas en su raíz". Así, "si nos situamos en el plano racional, por universalidad hacemos referencia a una titularidad de los derechos que se adscriben a todos los seres humanos"; además, "en el plano temporal, la universalidad de los derechos supone que tienen un carácter racional y abstracto al margen del tiempo y válidos para cualquier momento de la historia»; mientras que "en el plano espacial por universalidad entendemos la extensión de la cultura de los derechos fundamentales a todas las sociedades políticas sin excepción».

Bien puede decirse, entonces, que la universalidad actúa como punto de referencia complementario (y no como criterio contrapuesto) respecto de la afirmación, cada vez más frecuente a todos los niveles, incluido el internacional y el constitucional, de derechos específicos de determinados sectores de la población ${ }^{21}$.

No creemos, en efecto, que la afirmación de la universalidad de los derechos excluya la posibilidad de reforzar la protección de los mismos respecto de grupos concretos de personas. Al respecto, entiende MARTínEZ-PUJALTE (1995: 148) que tal observación no contradice la universalidad de los derechos, sino que constituye un nuevo argumento a su favor. Cuando se habla de derechos de un colectivo con-

los Derechos Fundamentales proclamada en el Consejo Europeo de Niza el 7 de diciembre de 2000, e incorporada como Parte II del Tratado por el que se establece una Constitución para Europa, "constituye buen botón de muestra del segundo plano en que se sitúa la Carta Social Europea». Al respecto, asimismo, Alegre MARtínez y Jimena Quesada (2005), y Jimena Quesada y Alegre Martínez (2005), Capítulo II.

${ }_{21}$ Por poner sólo algunos ejemplos, entre los muchos posibles: derechos de los niños (Convención de 20 de noviembre de 1989 sobre los derechos del niño, adoptada por la Asamblea General de las Naciones Unidas, artículo 75 de la Constitución venezolana, Ley venezolana de protección al niño y al adolescente [fecha], artículo 39 de la Constitución española), derechos de la mujer (Convención sobre la eliminación de todas las formas de discriminación contra la mujer, hecha en Nueva York el 18 de diciembre de 1979), derechos de los mayores y reivindicación de su papel activo en la sociedad (artículo 80 de la Constitución venezolana, y artículo 50 de la española; véase SEIJAS VILLADANGOS, 2004), derechos de los discapacitados (artículo 81 de la Constitución venezolana y artículo 49 de la española), derechos de los pueblos indígenas (artículos 119 a 126 de la Constitución venezolana) o, más recientemente, derechos de los sin techo, como proyección inmediata del ya comentado derecho a una vivienda digna. Así, "Un techo por derecho" fue el lema elegido para el "día de los sin techo" celebrado el 21 de noviembre de 2004 y promovido por Cáritas y la Federación de Asociaciones de Centros para la Integración y Ayuda a Marginados, FACIAM (Cáritas, n. ${ }^{\circ} 454$, noviembre 2004, pp. 12-13). 
creto, no se están formulando nuevos derechos humanos de los que sólo serían titulares los sujetos pertenecientes a esa categoría: no habría diferencia entre los derechos de los niños y los de los adultos, ni entre los de la mujer y los del varón, ni existen derechos de los que sólo sean titulares los niños, o las mujeres, o las minorías. "Lo que ocurre es lo contrario: precisamente porque los derechos son universales e iguales a todos los seres humanos, y habida cuenta de la realidad de que determinados colectivos [...] se encuentran, por unas u otras razones, en una situación social de particular desprotección e indefensión, se hace necesario enfatizar que a ellos también deben serle reconocidos los derechos humanos, concretar algunas de las exigencias de tales derechos en su situación particular, e instituir en su caso técnicas de protección específica».

Ello guarda a su vez relación con el concepto de discriminación positiva, y también con el tema, siempre actual, de lo que se han dado en llamar derechos colectivos (no sólo en el sentido en el que a veces se los considera, como derechos de tercera o cuarta generación, sino como la proclamación o materialización de un supuesto derecho a la diferencia $^{22}$. Respecto de esta posibilidad, estamos de acuerdo con MARINA y DE LA VÁlgoma (2000, 145-146, 199, 202, 282), cuando afirman que "la lucha por la no discriminación es más universal y está mejor fundada que la reivindicación de la diferencia». Es decir: está más correctamente fundamentada la reclamación del derecho a no ser discrimi-

22 Al respecto, HoRN (2004: 275-276): «La discusión de nuevas generaciones de derechos fundamentales, que se desarrollan crecientemente a partir de lo ya existente, lleva obligatoriamente a la cuestión problemática general de los derechos colectivos, que comprenden tanto los derechos sociales como también los derechos de los grupos, en especial minorías [...]. Los derechos colectivos representan una realidad en la experiencia política en torno a la cual se presentan grandes conflictos del presente, como también incluso dentro del neoliberalismo, como se ha reconocido por Friedrich Hayek. En el individualismo del presente se ha introducido una contradicción que lo limita contra voluntad, en concreto los derechos de las minorías, que exigen el reconocimiento de su identidad y peculiaridad cultural [...]. El respeto a los grupos hay que reducirlo al respeto del derecho individual a la pertenencia a un grupo, es decir, se concede la posibilidad de que determinados individuos posean derechos debido a su pertenencia a un grupo. En este contexto, resaltan los derechos de las mujeres, de la familia, de los niños o de los inválidos, pero también de las minorías étnicas cuya protección ha tenido entrada en medida creciente en los textos constitucionales iberoamericanos. A los derechos colectivos pertenecen también los derechos de los municipios, la autonomía de las universidades y los derechos de los trabajadores, como el derecho de huelga o la autonomía tarifaria». 
nado por una diferencia que el derecho a la diferencia: "lo importante es defender que no se puede privar a nadie de sus derechos personales por razones no legítimas". Y ello porque, como ya hemos visto, y en palabras de estos autores, "los derechos fundamentales se poseen por participar de la naturaleza humana. Ésta es la gran percha, el gancho trascendental del que dependen los derechos a la diferencia. No al revés. Las otras alternativas son peligrosas. Si se poseen derechos por poseer un rasgo no universal -el sexo, el color, la raza, la clase, la religión- estamos sometidos irremediablemente al dominio de la fuerza. Siempre es la fuerza la que impone la discriminación injusta».

Desde este punto de vista la universalidad entroncaría, en resumidas cuentas, con el principio de igualdad, lo cual explicaría a su vez la evidente dimensión constitucional (aunque ésta no sea la única) de los derechos y libertades fundamentales, habida cuenta de que, como ha escrito PÉREZ Royo (1996: 54, 55, 57), en el Derecho Constitucional "se expresa sin calificativos de ningún tipo el principio de igualdad": puesto que en él "se contempla al individuo no en lo que tiene de diferente, sino en lo que tiene de igual a todos los demás", sólo en el Derecho Constitucional "el principio de igualdad tiene vigencia de forma pura». Sin perjuicio de las consideraciones metodológicas que se añadirán más adelante en torno al necesario enfoque interdisciplinar para abordar el estudio de los derechos de la personalidad y los daños morales, nos quedamos con esta idea que, a su vez, nos permite avanzar un paso más en nuestra argumentación.

b) En efecto, y en segundo lugar, el dato de la constitucionalización de los derechos (Cfr. Alegre Martínez, 2003 a: 307 y ss.) resulta relevante por sí mismo, no sólo porque da buena muestra de la voluntad de elevar el reconocimiento y la garantía de los derechos al lugar más alto del Ordenamiento jurídico, sino además, porque es la causa de que para su comprensión no baste el enfoque civil o privatista.

A propósito del primero de estos aspectos, nos recuerda BISCARETTI (1982, 669 y ss.) que, a lo largo del siglo XIX, la enunciación de los derechos y deberes de los ciudadanos sufrió una doble transformación. En primer término, su subjetivización: pasó, desde las primeras Declaraciones de derechos de los siglos XVII y XVIII (aparte de precedentes más lejanos, como la británica Magna Carta Libertatum de 1215), al texto mismo de las Constituciones, lo cual les imprimió el carácter de normas jurídicas positivas (si bien de contenido más o menos general o de principio), valederas para los ciudadanos particulares de los respectivos Estados. Y, en segundo término, directamente relacionada con la primera, su positivización, término bajo el que este autor se re- 
fiere al hecho de que la proclamación de los derechos se combinara con la intervención de otras normas encaminadas a completar y detallar su regulación jurídica. Esta doble transformación, presente ya en las constituciones revolucionarias francesas posteriores a la de 1791 (que supuso el paso de las abstractas déclarations des droits a las garanties des droits, más jurídicas y normativas) tuvo su primera expresión íntegra en la Constitución belga de 1831, que a su vez inspiró en Italia el Estatuto Albertino de 1848, y que más tarde sería acogida también por todas las constituciones liberales y democráticas de las décadas siguientes (constitucionalización de los derechos).

Esa progresiva definición de las características de los derechos, paralela a la evolución de su reconocimiento por las constituciones, experimenta un impulso decisivo tras la primera Guerra Mundial. Como nos sigue indicando el citado autor, si hasta ese momento los derechos y deberes de los ciudadanos habían sido formulados jurídicamente sólo en relación con la actividad jurídica del Estado (la necesaria para alcanzar sus fines esenciales, y en concreto, teniendo en cuenta la tutela del orden interior del Estado, principalmente sobre la base de los principios democráticos de libertad e igualdad), desde esa época fueron definidos, también, respecto de la actividad social del Estado, ligada a las ideas de bienestar y progreso, trayendo consigo un considerable incremento de la extensión de los textos constitucionales. Claro ejemplo de ello sería la Constitución alemana de Weimar (1919), modelo en el que, a su vez, se inspiraron los demás Estados democráticos de la primera posguerra. Esa orientación se mantendría también en las constituciones aparecidas en las siguientes décadas (como la de la Segunda República española, en 1931, o la irlandesa de 1937; y se ha mantenido también, en buena medida, en las constituciones posteriores a la segunda guerra mundial (italiana de 1947, alemana de 1949, etc.). Además, la evolución posterior ha traído consigo, como nueva característica de los derechos, su progresiva internacionalización (RODRíGUEZ-ZAPATA, 1996: 295).

Estas pinceladas históricas, a pesar de su brevedad, pueden ayudarnos comprender mejor el papel que los derechos han venido ocupando en el contexto del Ordenamiento jurídico en su conjunto, en función de las características de su proclamación constitucional. Pero hay aún un último aspecto que debemos considerar dentro de este apartado: precisamente porque se insertan en el conjunto del Ordenamiento jurídico (del que la Constitución forma parte), y también por las muy diversas características y connotaciones de los bienes jurídicos protegidos a través de su constitucionalización, la reflexión sobre los derechos y libertades fundamentales (y concretamente, por lo que en 
esta obra nos ocupa, sobre los derechos de la personalidad) deberá llevarse a cabo desde un enfoque interdisciplinar, que los contemple desde perspectivas, más que diversas, complementarias.

En efecto, es generalmente afirmada la concurrencia de las dimensiones constitucional y privatista en relación con los derechos de la personalidad o con situaciones o fenómenos jurídicos en los que éstos puedan verse comprometidos. Así, por ejemplo, PEgORARo (2004: 23), tomando como referencias comparativas las constituciones italiana y española, ha puesto de relieve las «implicaciones sobre el Derecho Constitucional» que presentan determinados "aspectos vinculados a Internet y el Derecho privado, al comercio electrónico y otros temas ampliamente estudiados por la ciencia civilista», así como el hecho de que "las materias referidas a la intimidad personal y de la imagen [...], también tocan de cerca la esfera privatista». Por su parte, GARCíA GARCíA (2003: 30), encontrando elementos comunes entre los derechos fundamentales en general, y los derechos de la personalidad en concreto, entiende que "para la defensa de los derechos de la personalidad, construcción de la dogmática iusprivatista, como de los derechos fundamentales y constitucionales, construcción de la iuspublicista, la dignidad y la libertad han asumido protagonismo esencial caracterizándose como valores superiores cuya función en el ordenamiento jurídico es la de inspirar normas básicas del Derecho que, a su vez, ha de interpretarse conforme al contenido de aquellos [...]. Tal característica les procura el papel de indisociables de los derechos fundamentales, y en particular de los derechos inherentes a la persona".

Esta imbricación de las perspectivas civil y constitucional en torno a los derechos de la personalidad, no sólo lleva consigo la necesidad de adoptar determinadas pautas en el orden metodológico a la hora de proceder al estudio de los mismos (como se expondrá en el apartado 3.2), sino que implica también una destacable consecuencia práctica: cuando se ve afectado un derecho de la personalidad (y por tanto se causa, al menos, un daño moral (como quedó expuesto en el apartado 1), la víctima es quien mejor conoce la intensidad del daño que se le ha causado, y por tanto, debe poder participar en el diseño del resarcimiento que más le conviene ${ }^{23}$. Además, el criterio del juez, por más que

${ }^{23}$ En el supuesto español, y a propósito de los derechos al honor, intimidad y propia imagen, es de destacar la diversidad de vías procesales encaminadas a su protección (vid. Alegre MARTíneZ, 1997: 153 y ss.). El artículo 9.1 de la Ley orgánica 1/1982 de 5 de mayo, de protección civil del derecho al honor, a la intimidad personal y familiar y a la propia imagen, establece que «La tutela judicial frente a las in- 
deba estar jurídicamente fundamentado, no puede ser el único a la hora de medir el daño causado, sino que la participación de la propia víctima y el asesoramiento de expertos se revelan como inexcusables.

Por último, esa capacidad de elección por parte de la víctima, no tiene por qué verse reducida únicamente a escoger una u otra acción procesal de entre el abanico que ofrecen los distintos ordenamientos jurídicos (acción de resarcimiento por daño moral, acción penal, acción de amparo, etc.), sino que bien podría llegar a incluir la posibilidad, menos traumática y más satisfactoria de lograr la paz entre el agresor y la víctima a través de la mediación y de la Justicia de Paz. Esta figura, prevista en el artículo 258 de la constitución venezolana, y fomentada a través de la legislación de dicho país [fecha] y de su creciente aplicación, se ha revelado como una vía inmediata e instantánea, que satisface las legítimas aspiraciones de justicia evitando los formalismos y dilaciones

tromisiones ilegítimas en los derechos a que se refiere la presente Ley podrá recabarse por las vías procesales ordinarias o por el procedimiento previsto en el artículo 53.2 de la Constitución. También podrá acudirse, cuando proceda, al recurso de amparo ante el Tribunal Constitucionalı.

La pluralidad de cauces de protección de estos derechos obedece, en opinión de ESPÍN (2003: 233), a varias causas: "el carácter personalísimo de los mismos —que puede determinar la falta de voluntad de perseguir determinadas infracciones-, la necesidad de graduar y matizar al máximo la respuesta que el ordenamiento debe dar a tales infracciones - necesidad en gran medida determinada por la protección reforzada de las libertades de expresión e información, bajo cuya advocación se producen los más frecuentes atentados al honor, la intimidad y la propia imagen-, la pluralidad de efectos de semejantes infracciones para quienes las padecen - personales, económicos y profesionales-, etc., han llevado a los ordenamientos modernos a arbitrar diversos cauces de protección de estos derechos, que en el caso español son tres: el derecho de rectificación [Ley orgánica 2/1984 de 26 de marzo], la protección civil con contenido indemnizatorio [Ley orgánica 1/1982, citada], y la protección penal [reservada para los ataques más graves a estos bienes jurídicos]». En definitiva, continúa este autor (ibidem, p. 235), "esta pluralidad de vías de protección es absolutamente imprescindible», en cuanto que "la persona ha de poder modular el alcance de la satisfacción que pretende, puesto que en muchos casos la reacción más fuerte (la penal) o, incluso, la civil, puede ocasionar más perjuicios todavía, debido a la publicidad que la misma conlleva, que vuelve a proyectar atención pública sobre la ofensa. Lo cual lleva, en muchas ocasiones, a que la persona ofendida prefiera no ejercer acción alguna, en especial si la única respuesta fuese la penal, que siempre ocasiona una mayor repercusión social». Por eso, y con carácter general, las diversas vías de protección se presentan como "alternativas, pudiendo el ciudadano escoger la que considere más conveniente a sus intereses", como puede apreciarse por ejemplo en la Sentencia del Tribunal Constitucional 241/1991 de 16 de diciembre. 
que suelen acompañar a los procedimientos judiciales, fomentando además la dimensión participativa. Mediación y Justicia de Paz se perfilan, pues, como medios eficaces de prevención y restitución no litigiosa de los derechos de la personalidad ${ }^{24}$.

\subsection{Individualidad versus individualismo}

Las anteriores consideraciones, han tenido como objetivo presentar la dinámica del gradual reconocimiento de los derechos y libertades, y su incremento cuantitativo y cualitativo, como consecuencia del desarrollo de la idea de individualidad en una dirección siempre creciente, no sólo en cuanto a la consciencia de la misma, sino también en lo referente a las exigencias que de ella se derivan.

Ahora bien: el contrapunto a esta tendencia lo encontramos en el riesgo, en buena medida materializado, de que esa tendencia traiga consigo lo que podríamos Ilamar una hipertrofia de la individualidad, a la que bien nos podemos referir como individualismo, sobre cuyos peligros como caldo de cultivo del despotismo en el contexto democrático ya advertía en 1840 TOCOUEVILLE (2004: 128 y ss.) $)^{25}$.

En algún trabajo anterior (AlEgRE MARTíneZ, 2005: 49-50) nos hemos preguntado qué ocurre cuando la Constitución proclama la dignidad de la persona y reconoce sus derechos inviolables, mientras la mentalidad supuestamente mayoritaria asume -cómplice, indolente o resignada- la validez de prácticas y planteamientos que, lejos de materializar

24 GutiéRREZ GutiéRREZ (2004: 342) constata un «desarrollo desequilibrado del Estado constitucional, en el que se ha difuminado la naturaleza política de los derechos fundamentales y se ha sobrevalorado su tutela judicial», la cual proporciona una protección "por demás limitada".

25 Define este autor el individualismo en el volumen 2 de La democracia en América como "un sentimiento reflexivo y apacible que induce a cada ciudadano a aislarse de la masa de sus semejantes y a mantenerse aparte con su familia y sus amigos; de suerte que después de formar una pequeña sociedad para su uso particular, abandona la grande a su destino». A diferencia del egoísmo ("amor apasionado y exagerado hacia la propia persona que induce al hombre a no referir nada sino a uno mismo y a preferirse en todo", el cual "nace de un instinto ciego»), el individualismo "procede de un juicio erróneo más que de un sentimiento depravado", que ues propio de las democracias y amenaza con desarrollarse a medida que las condiciones se igualen" (pp. 128-129). Sin embargo, en páginas posteriores (133 y ss.) explica "Cómo frenan los americanos el individualismo con instituciones libres". 
la voluntad del constituyente, reflejan y fomentan el individualismo insolidario, la violencia en sus más diversas manifestaciones y la relativización o pérdida de valores como el respeto a la vida de todos los seres humanos y a los derechos de los demás, y generan situaciones en las que la vida no se desarrolla de acuerdo con esa dignidad.

Da la sensación, en efecto, de que estamos llegando a una situación de invocación desproporcionada de los derechos (sobre todo de los propios, no tanto de los ajenos), en la que todo se considera un derecho, y todo nos es debido. En definitiva, hemos adoptado como modelo "un individualismo del sálvese quien pueda, que desvincula sin vincular después" (MARINA, 2004: 153) ${ }^{26}$.

Resulta fácil, entonces, establecer la conexión que permite reflexionar sobre esta realidad tomando como referencia el papel de la educación en el logro del libre y pleno desarrollo de la personalidad (vid. supra, apartado 1, y ALEGRE MARTínEZ 2002 b), y la necesidad de incidir en los deberes como necesaria contrapartida de los derechos: la educación, vista desde los derechos y deberes, se convierte en un valor humano que preserva la individualidad, y actúa como antídoto frente al individualismo.

Desde este enfoque, la educación para el conocimiento y el disfrute de los derechos, no podrá ir separada de la constatación de que los derechos "no son algo que se consiga de una vez por todas"; y que, especialmente en esta materia, "los logros son frágiles y precarios" (MARINA y DE LA VÁLgOMA, 2000: 95, 169). Buena cuenta de ello nos la da el que los medios de comunicación sigan haciéndose eco de noticias relacionadas con tráfico de personas para su explotación de toda índole o el hecho de que, como recuerdan estos autores, haya países en los que continúa habiendo esclavos, por desconocer que la esclavitud se ha abolido formalmente.

Además, dicha perspectiva de la educación tampoco podrá dejar de lado la idea de participación: si la educación posibilita el respeto e interiorización de los derechos, libertades y deberes, no es menos cierto que la proyección de los mismos hacia una sociedad libre, justa, de-

26 Pone como ejemplo este último autor (p. 152) lo frecuentemente que se repite la frase 'tengo derecho a equivocarme': "Es como si alguien dijera: 'tengo derecho a estar enfermo'. Se tendrá derecho a elegir la propia vida, a dejarse guiar por las propias creencias, pero el error siempre será una mala consecuencia de un derecho, pero no un derecho en sí». Resulta observable también la tendencia a transferir la responsabilidad a la sociedad, "con lo que la responsabilidad individual queda amortiguada". 
mocrática, tolerante y solidaria sólo podrá hacerse efectiva en un contexto social participativo, y partiendo de una adecuada pedagogía de los derechos. Ésta pasaría por un correcto entendimiento de los mismos: por una parte, presentándolos como limitados y haciendo hincapié en esos límites (BRAGE CAMAZANO, 2004). Y por otra, planteando una concepción de los derechos que, de nuevo en palabras de MARINA y DE LA VÁlGOMA (2000: 189 y ss., 192 a 197, 229, 269 a 271) vaya más allá de la "comodidad individualista, más dada a la reclamación que a la ayuda", y los contemple como elementos esenciales de un sistema que "nos integra en una tupida red de reciprocidades". Es preciso que los estudiantes (los cuales fuera - y también dentro- del aula son, además, ciudadanos y personas), perciban que "la buena comprensión de lo que es un derecho no nos encierra en el egoísmo sino que nos abre a la reciprocidad" encontrando en los deberes su lógica contrapartida; que los derechos y libertades "permiten y exigen a la vez. Conceden y reclaman. Cuando conseguimos un derecho contraemos al tiempo una deuda", que nos obliga a hacer un uso racional y responsable de los mismos ${ }^{27}$.

27 Muchos serían los ejemplos en que esta idea puede y debe concretarse: así, la libertad de expresión o la libertad de conciencia no pueden separarse de la exigencia de una actitud tolerante y ajena al fanatismo; el derecho a la participación política mediante el derecho de sufragio Ilevará consigo el deber cívico (aunque no exigible hoy jurídicamente en España) de votar, contribuyendo así a la formación de la voluntad popular representada en el Parlamento, etc.

Las Declaraciones que marcan el surgimiento histórico de los derechos, tal y como recuerdan los autores citados, surgen como reacción frente al poder y la tiranía, y sus redactores relacionaban los deberes con la idea de opresión (por ejemplo, la Declaración Universal de 1948 les dedica un único artículo, el 29).

Más desarrollada y explícita resulta la presencia de los deberes en los textos constitucionales. En la Constitución venezolana, se recogen en un capítulo específico (el $\mathrm{X}$ del Título III, título que a su vez lleva como rúbrica "De los deberes, derechos humanos y garantías»), mencionándose el "deber de honrar y defender a la Patria», el de "cumplir y acatar la Constitución», el de participación política, civil y comunitaria, así como los deberes tributarios, la prestación del servicio civil o militar, y la solidaridad social, además de otros deberes dispersos a lo largo del texto, específicamente dirigidos a los funcionarios y poderes públicos. El artículo 76, en su párrafo segundo, establece que "El padre y la madre tienen el deber compartido e irrenunciable de criar, formar, educar, mantener y asistir a sus hijos e hijas, y éstos tienen el deber de asistirlos cuando aquél o aquélla no puedan hacerlo por sí mismos".

En España, como ha indicado MoLAs (2003: 296-298), los diversos deberes recogidos en nuestra Constitución a lo largo de su articulado precisan una acción positiva por parte de los ciudadanos, y serán exigibles de acuerdo con su configuración legal, la cual debe ser expresión y concreción del deber constitucional, estando en la Constitución su justificación, límite y garantía. Junto al deber genérico derivado de 
En suma, podemos quedarnos con la importante enseñanza de que, el asumir deberes, "va indisolublemente unido" con exigir derechos: "Querer lo contrario, esto es, tener derechos sin obligaciones, es propio de niños o, lo que es mucho peor, de hombres que no quieren asumir sus responsabilidades" (Oliver Arajujo, 2003: 136). Por eso, no es menos cierto que "una autonomía responsable es un recurso indispensable para el buen vivir» (MARINA, 2004: 153).

Así las cosas, no parece posible ni conveniente un modelo educativo que prescinda de aquellos contenidos que despierten en el alumno la conciencia de su humanidad desde una perspectiva que contemple sus derechos y obligaciones desde una perspectiva armónica y complementaria. Educar en, desde y para el respeto a la dignidad propia, pero también ajena, significa despertar la sensibilidad y potenciar el sentido crítico hacia la realidad que nos toca vivir. Seguramente, si queremos que la educación sea, a todos los niveles, un instrumento de progreso, tendremos que empezar orientando nuestra enseñanza hacia la búsqueda de alternativas frente a todo aquello que nos deshumaniza.

la dignidad de la persona (artículo 10.1), en virtud del cual cada uno debe respetar los derechos de los demás (Alegre Martínez, 1996: 75, 86 y ss.), nuestra Norma básica recoge referencias a los deberes en diversos preceptos: así, se refiere al deber de conocer el castellano (art. 3.1), a la defensa de España como derecho y deber de los españoles (art. 30.1), al derecho al trabajo y deber de trabajar (art. 35), a los relacionados con la salud pública (art. 43.2), o al de conservar el medio ambiente (art. 45.1 CE). La necesidad de mediación de una ley para la eficacia de los deberes se deduce del art. 31.3, según el cual «Sólo podrán establecerse prestaciones personales o patrimoniales de carácter público con arreglo a la ley". Otros deberes constitucionalmente reconocidos son el de recibir la enseñanza básica (art. 27.4), el de cumplimiento de las sentencias judiciales y colaboración con la Administración de Justicia (art. 118), o el de acudir a las Comisiones de Investigación de las Cámaras (art. 76.2). Pero cuando el constituyente se ocupa de los deberes específicamente ("De los derechos y deberes de los ciudadanos", sección segunda del capítulo segundo del Título I), menciona sólo tres concretos: el derecho y deber de defender a España (art. 30.1), el derecho y deber de trabajar (art. 35) y el deber de contribuir al sostenimiento de los gastos públicos (art. 31). El texto constitucional recoge también, dentro de esta misma sección, una referencia genérica a los deberes en situaciones de emergencia: "Mediante ley podrán regularse los deberes de los ciudadanos en los casos de grave riesgo, catástrofe o calamidad pública" (art. 30.4), así como la posibilidad de establecer "un servicio civil para el cumplimiento de fines de interés general» (art. 30.3). El artículo 32.2 alude también a los derechos y deberes de los cónyuges, que deberán ser regulados por ley. 


\section{LA CONSIDERACIÓN DEL DAÑO MORAL COMO LESIÓN DE LA INTEGRIDAD Y DEL LIBRE DESENVOLVIMIENTO DE LA PERSONALIDAD}

\subsection{Contextualización del daño moral}

Llegados a este punto, comprobamos que las diferentes piezas y elementos con los que venimos trabajando en estas páginas introductorias, comienzan a encajar a los efectos de construir el marco teórico en el que situar y establecer el vínculo entre los derechos de la personalidad y los daños morales.

Dicho vínculo quedaba ya planteado al principio de este trabajo: cuando se afectan los derechos de la personalidad siempre se causa, al menos, un daño moral. Puede hablarse, entonces, recapitulando, de una identidad absoluta, no sólo porque una lesión de los derechos de la personalidad causa siempre un daño en la esfera moral del individuo, sino además, porque ambos afectan la integridad del ser humano, derivación a su vez del libre desenvolvimiento de la personalidad.

Esa es la razón de que, a la hora de ubicar el daño moral dentro del mencionado marco teórico, cobre especial protagonismo el derecho a la integridad como derecho de la personalidad. Si, como vimos más arriba, la constitucionalización de este derecho no sólo abarca la vertiente física, sino también la psíquica y moral, en este momento podemos ya apreciar que ello se debe a la pluralidad de facetas que se haIlan presentes en la propia idea de personalidad. En efecto, los expertos afirman que "la personalidad es una organización dinámica, en movimiento, en donde confluyen los aspectos físicos, psicológicos, sociales y culturales de un individuo" (RoJAs, 2005). Ello no sólo nos plantea la ya aludida necesidad de adoptar para su estudio a nivel teórico una perspectiva interdisciplinar (sobre la que volveremos en el apartado siguiente), sino que reclama una nueva necesidad, esta vez a efectos garantistas y prácticos: la búsqueda de una protección integral de los derechos de la personalidad, basada en la prioridad y el interés superior de los mismos, que debe conducir, en definitiva, a la protección integral de la persona, de su individualidad y de todos sus bienes e intereses, lo cual, como también veíamos anteriormente, supone un paso más respecto de la mera protección de los derechos. La persona pasa a ser considerada, así, como algo más que sus propios derechos, los cuales, de algún modo, cobran vida propia respecto de aquélla. Con lo cual tenemos que la violación de los derechos de la personalidad incluye tanto la vulneración del derecho como la lesión o quebranto de la integridad de la persona. $Y$, puesto que dicha integridad incluye también la 
vertiente moral, queda verificada nuestra hipótesis de partida, que asocia la violación de un derecho de la personalidad con la causación de un daño moral.

Así pues, y en lo que atañe a este trabajo, el derecho de los daños morales queda configurado como el derecho del sufrimiento, esto es, como la búsqueda de la justicia que debe aplicarse para disminuir ese sufrimiento.

No estará de más poner de manifiesto la dificultad de cuantificar el agravio, el perjuicio o el dolor causado por un daño moral, la imposibilidad de una valoración completa y cabal del mismo por parte del juez sin las aportaciones de expertos en otras ciencias (psicólogos, trabajadores sociales, etc.), o la ilimitada variedad posible de daños morales, habida cuenta de la contrastada capacidad del ser humano para inventar nuevas formas de perjudicar a sus semejantes, lesionando o menoscabando su patrimonio mora ${ }^{28}$. Sin olvidar la doble dimensión del daño moral, tanto de orden privado o de protección del interés de los particulares (que explica su tratamiento en los códigos civiles, como sucede, por ejemplo, en el artículo 1196 del Código Civil venezolano), como de orden público, al estar en juego derechos humanos que protegen bienes jurídicos inquebrantables e indisponibles, como el honor, la intimidad, o la propia vida. Bien entendido que el orden público, al interesar al Estado, interesa a la sociedad entera, ya que toda la comunidad se resiente y se ve afectada por la violación de los derechos de uno de sus miembros.

Baste en este momento considerar que el vínculo que venimos poniendo de manifiesto entre derechos de la personalidad y daños morales (daño moral como lesión de los derechos de la personalidad) nos pone sobre la pista sobre el hecho de que, a cada uno de los dos términos del binomio les afectan, a su vez, dos órdenes de problemas o cuestiones que configuran o delimitan el marco teórico:

a) Así, respecto de los derechos de la personalidad, se plantea una necesidad de doble deslinde conceptual:

28 La expresión "patrimonio moral», presente en el artículo 1 de la Constitución venezolana, referido a la propia República, junto con los valores de «libertad, igualdad, justicia y paz internacional» en que ésta se sustenta, encuentra su proyección a nivel individual en el ya citado artículo 46, que reconoce el derecho de toda persona al respeto de su «integridad física, psíquica y moral». En la Constitución española, como también vimos, el artículo 15 reconoce, junto con el derecho de todos a la vida, el derecho a la "integridad física y moral, sin que, en ningún caso, puedan ser sometidos a tortura ni a penas o tratos inhumanos o degradantes". 
- En primer lugar, salvada la necesidad de determinar con precisión el perfil de los derechos frente a otros aspectos susceptibles $y$ dignos de protección (bienes, intereses, necesidades), habrá que insistir en que el fin último de la protección integral de la persona pasa por la salvaguardia de todos ellos, y no sólo de los derechos. En este sentido, la protección general de todos aquellos aspectos que impliquen la promoción del ser humano, de su quehacer y de sus potencialidades, debe ser estimulada a fin de que progrese verdaderamente la sociedad. Este avance va más allá del aumento del bienestar material o del desarrollo económico, y debe extenderse a la promoción de todos los valores de la persona. Cuando los textos constitucionales reconocen los derechos, deberes y libertades fundamentales, están posibilitando el desarrollo de la personalidad al lado del puramente económico. Esa es la razón de que las constituciones contemplen medidas que, junto con el individuo aisladamente considerado, protejan también instituciones, como la familia, la paternidad, la infancia, etc. (piénsese, por ejemplo, en los artículos 18.1 —intimidad familiar-, 32 ó 39 de la Constitución española), en las que el Estado tiene un interés directo, perfectamente identificable con el interés de las propias personas: en este contexto, el Estado no puede concebirse como un ente distinto de las personas que lo integran. Resulta fácil entonces conectar esta idea con la que más arriba exponíamos en el sentido de que la causación de un daño moral (bien sea por parte de los poderes públicos o de los particulares $^{29}$ ) no sólo afecta a la persona agraviada, sino a toda la sociedad, ya que se ven involucradas instituciones que conforman su propia organización y estructura.

- Sentada esta consideración previa, y ya en referencia específica a los derechos, habrá que responder a la cuestión de qué cuáles deben ser considerados propiamente derechos de la personalidad. Frente a concepciones más restringidas, a las que ya nos hemos referido en el apartado 2.1, que sólo incluyen en este grupo a unos pocos derechos, «instrumentos ideados por el Ordenamiento jurídico para que el hombre satisfaga aquellas necesidades" que le permitan "conseguir el pleno goce y disfrute de aquellas manifestaciones esenciales de su personalidad", y que serían concretamente los derechos a la vida, a la integridad, al honor y a la intimidad (Bustos PUECHE, 1997: 25 y 46-47), es posible tomar como referencia una enumeración más amplia de de-

29 Como aportaciones en este aspecto, en el ámbito iberoamericano, citaremos el trabajo de Julio Estrada (2000). En España, García ToRRES y JimÉnEZ-Blanco (1986), Bilbao Ubillos (1997) y NARANJo de LA CRUZ (2000). 
rechos de la personalidad. En ésta, bien podrían entenderse como tales, junto con los que se acaban de mencionar, todos aquellos derechos encaminados a que no se vea lesionada cualquiera de las características, dimensiones o exigencias que atribuíamos a la individualidad: la irrepetibilidad, la integridad en su más amplio sentido, la incolumidad, la intangibilidad o, en definitiva, ese aludido derecho a ser lo que se es. Estaríamos, desde esta perspectiva, ante un amplio elenco de derechos expresados como una lista abierta a la que pueden incorporarse derechos que, incluso no estando expresamente recogidos en la Constitución, resulten igualmente dignos de protección en cuanto inherentes al ser humano (recuérdese el concepto de derechos innominados al que hacíamos referencia en el apartado 2.2, que ha encontrado eco en el artículo 22 de la Constitución venezolana). Un término medio entre ambas concepciones lo encontraríamos en una enumeración cerrada, aunque más amplia, de "elementos de ese núcleo insoslayable sin el cual sólo en apariencia (o con cinismo) se puede hablar de democracia (SÁNCHEZ FERRIZ y JIMENA QueSADA, 1995: 36 y ss.). Estos autores consideran como tales los derechos a la vida y a la integridad física y moral, la libertad personal en sentido amplio, el derecho a la tutela efectiva de jueces y tribunales y los correspondientes derechos procesales, el derecho a la vida privada y a una vida digna, y los que tradicionalmente se conocen como libertades públicas: libertad de pensamiento y su libre expresión, libertad de reunión, de asociación, y de culto, todas ellas "expresión de la naturaleza sociable del individuo". La enumeración de este "núcleo duro de los derechos humanos" concluiría, para estos autores, con el derecho a la igualdad, que, propiamente, "no es un derecho, no tenemos derecho a ser iguales, lo somos sin más».

b) En relación con los daños morales, será preciso aludir a una doble dificultad, esbozando al mismo tiempo alguna vía de solución:

- En primer lugar, la planteada a la hora de probar el daño moral causado, o de medir o cuantificar la lesión infligida a lo que hemos denominado patrimonio o esfera moral de la persona, pues normalmente sólo la víctima podrá conocer la intensidad del daño, y no siempre le será fácil hacérsela conocer a terceros. Quizá esa dificultad (conocida como difficilioris probatio) puede irse superando en la medida en que la formación y la sensibilidad del juzgador vayan liberándole de prejuicios, por ejemplo, hacia el análisis y el reconocimiento de daños psicológicos. Evidentemente, y como hemos señalado con anterioridad, sólo la ayuda y el asesoramiento de expertos en diversas disciplinas puede contribuir a formar el juicio sobre la magnitud del daño moral, 
cuya prueba es ya una exigencia que ha ido incorporándose a los distintos sistemas jurídicos ${ }^{30}$.

- Nos encontramos, por último, con el difícil resarcimiento del daño moral, si es que resulta posible su total subsanación o reparación. La declaración de que efectivamente se ha ocasionado un daño moral tendrá que ir encaminada a procurar la satisfacción del ofendido, mediante un intento por parte del juez de restituir la situación jurídica infringida. Lo que ocurre es que, especialmente tratándose de daños morales, siempre existirá el riesgo de que esa restitución tenga un carácter más formal que real. Se ha escrito al respecto que «los derechos fundamentales, con ser el mayor logro del constitucionalismo democrático, o forman parte de la cultura y del comportamiento social y político (sobre los que tanto ha aleccionado Häberle) o, contempladas sus garantías como técnicas de protección frente a sus violaciones, aquéllas acaban siendo simples mecanismos ortopédicos que difícilmente reparan el daño sufrido; a diferencia de lo que ocurre en el Derecho privado, la reparación material no subsana el atentado a un derecho fundamental; y la satisfacción moral por una resolución estimatoria suele ser bien pequeña si se la compara con el desgaste psicológico (y la incertidumbre por el fallo) que todo proceso jurisdiccional comporta" (SÁNCHEZ FERRIZ, 2000: 19). Así las cosas, sólo una efectiva posibilidad de participación de la víctima en el diseño de la modalidad de resarcimiento que más le conviene (a ello nos referíamos al final del apartado 2.2) podrá dar satisfacción, al menos parcialmente, a la necesidad de la víctima de que se haga justicia.

\subsection{Consecuencias metodológicas}

De cuanto llevamos expuesto, se deriva la necesidad de adoptar unas determinadas premisas metodológicas a la hora de aproximarnos a los derechos de la personalidad y a los daños morales como objeto de nuestro estudio:

a) Por una parte, el enfoque comparatista, el recurso al Derecho comparado "puede ser de ayuda a este propósito, allí donde sugiere las metodologías adecuadas para servirse de ciencias 'distintas' con el propósito de conseguir el resultado típico y prioritario, el conocimiento, sea en los estudios puramente comparatistas o en aquellos de Derecho

30 Véase, por ejemplo, la sentencia de la Corte de Apelaciones de Santiago de Chile, de 30 de mayo de 2001, Rol n. ${ }^{\circ} 25.892-2001$. 
interno" (PEgORARO, 2004: 17-18). La comparación jurídica resulta imprescindible en un campo como el que aquí nos ocupa, no sólo por la "circulación, siempre intensa, de los modelos", que "impide estudiar las instituciones propias del Derecho Constitucional sin tener en cuenta las influencias que provienen del exterior" (PEGORARO, 2001: 26), sino también por la claridad que este enfoque puede aportar al análisis de un tema en el que concurren, como quedó dicho más arriba (apartado 2.2), las dimensiones constitucional y privatista. Pero además, la comparación resulta ineludible si tenemos en cuenta que los problemas que surgen en torno a los derechos de la personalidad y a los daños morales tienen como centro a la persona, y por tanto, revisten un carácter universal. A su vez, esta es la razón por la que no podemos quedarnos en el plano de la especulación teórica: el daño moral se causa sobre una persona, no sobre un ente abstracto o inmaterial. $Y$, en este sentido, "si la finalidad básica del derecho público comparado consiste en organizar sistemáticamente el conocimiento en el sector que le corresponde, su misión no se agota con la simple investigación teórica, con meros fines especulativos. Como otros aspectos del conocimiento humano, el resultado de la investigación puede ser utilizado también a nivel práctico" (PEgoraro, 2002: 37).

b) De otro lado, en varios lugares de estas páginas venimos haciendo referencia a la necesidad de un enfoque interdisciplinar en el estudio de los daños morales como lesión de los derechos de la personalidad. $Y$ en este punto también es necesario argüir varias razones que justifican esta opción metodológica.

No sólo se trata, como venimos señalando hasta ahora (apartados $2.2,3.1)$, de la necesidad de lograr una protección integral de la persona más allá de la protección de los derechos. Ciertamente, hemos tratado de ver cómo con la protección jurídica de los derechos se dejan a un lado otros aspectos que son necesarios para conformar una protección humanitaria integral. Esta materia, por tanto, la interdisciplinariedad se revela como fundamental para lograr el objetivo marcado por los principios de prioridad absoluta, interés superior y de protección integral de la persona. No basta, pues, la protección a sus derechos, sino que para lograr dicho objetivo es necesario integrar a la familia, educarla, sensibilizarla, para lo cual resulta necesaria la intervención de especialistas que manejen herramientas diferentes a las manejadas por los juristas. Cada uno podrá aportar elementos para la comprensión del fenómeno familiar como son los psicólogos, psiquiatras, antropólogos, trabajadores sociales, sicólogos sociales, artistas y educadores. El papel que el proceso educativo está llamado a desempeñar vuelve a revelarse como fundamental (vid. supra, apartados 1, 2.1, 2.3). 
Lo que ocurre, además, es que, incluso dentro del ámbito jurídico resulta imprescindible la complementariedad de enfoques. Si la vertiente patrimonial de determinados derechos de la personalidad (honor, intimidad, propia imagen) ha motivado que en buena medida se haya dedicado a ellos la doctrina civilista ${ }^{31}$, ello no obsta para afirmar, como aquí venimos haciendo, su evidente dimensión constitucional. Ésta, no sólo viene dada por el hecho de la constitucionalización de estos derechos (vid. supra, apartados 1 y 2.2), a raíz de la cual los derechos de la personalidad no pueden ya estudiarse exclusivamente desde la perspectiva del Derecho Civil; sino, además, por el propio carácter troncal que posee el Derecho Constitucional dentro del Ordenamiento jurídico.

A este respecto, y en relación con el caso español, es ya sobradamente conocido y comentado que la irrupción de la Constitución de 1978 ha afectado a todos los sectores del Ordenamiento. Como ha puesto de relieve GARCIA CUADRADO (1998: 37), "el Derecho constitucional es, hoy por hoy, el supremo Derecho positivo, de forma que todas las ramas jurídicas [...] se encuentran, en principio, sometidas al Derecho constitucional. Hasta tal punto esto es así que los principios fundamentales de todas ellas se encuentran en la Constitución y son por tanto también Derecho constitucional», papel que en el pasado ocupara el Derecho Natural, sin perjuicio de que en buena medida sea el Derecho internacional el que actualmente esté adquiriendo el carácter de «nuevo Derecho supremo, por encima incluso de la legalidad constitucional de los Estados». También FernándeZ-CARVAJAL (1989: 43) considera "correcta la calificación del Derecho Constitucional actual como un Novísimo Derecho Común que informa y orienta al resto del ordenamiento". En la misma idea incide gráficamente PÉREZ RoYo (1996: 57) cuando señala que "el Derecho Constitucional es lo único que tienen en común todos los demás Derechos. El Derecho Constitucional es el portador de los elementos más simples y generales a partir de los cuales se constituyen todos los demás Derechos. Sin el Derecho Constitucional el resto del Derecho resulta ininteligible. No es, en consecuencia, como se suele decir con frecuencia, el punto del partida del Derecho público, sino el punto de partida de todo el Derecho, tanto del público como del privado. El Derecho no tiene más que un tronco, que es el Derecho Constitucional. Y solamente tiene un tronco, porque únicamente en él se expresa sin calificativos de ningún tipo el principio de igualdad. La igualdad es el Derecho y la igualdad en cuanto tal sólo está

31 Baste citar a este respecto, a modo de ejemplo, los trabajos de CASTÁN TOBEÑAS (1952), De Castro (1959), Beltrán de Heredia (1976), Romero Coloma (1985), HerreroTejedor (1994), Bustos Pueche (1997). 
presente en el Derecho Constitucional». Esta última idea encuentra fácil conexión con lo expuesto en el apartado 2.2 en torno a la universalidad de los derechos humanos ${ }^{32}$.

Por lo demás, la dimensión pública del daño moral, en cuanto que de algún modo toda la comunidad se ve afectada si se vulneran los derechos de uno de sus miembros, (vid. supra, apartado 3.1), y la necesidad de resarcimiento como exigencia de orden público que de ahí se deriva, sirven, junto con lo que se acaba de indicar sobre el carácter del Derecho Constitucional como Derecho común, para reafirmar la necesaria concurrencia de éste con el Derecho Civil en materia de daños morales. Podría hablarse, así, de un Derecho de los daños morales como punto de encuentro entre el Derecho Civil y el Derecho Constitucional, presentando a la vez perfiles diferentes respecto del Derecho penal, del Derecho civil aisladamente considerado, e incluso del propio Derecho de los derechos humanos (pues, como vimos, buscaría la protección y promoción integral de la persona, no sólo la satisfacción procesal de sus derechos). De hecho, no resulta ya extraña en diversos países (valga el ejemplo de Argentina) la denominación Derecho de Daños, como disciplina separada del Derecho Civil y de la propia idea de responsabilidad civil ${ }^{33}$.

De todo ello, no dejan de extraerse también consecuencias de orden práctico que tendrán que ver, por un lado, con la estrecha vinculación que debe existir entre el sistema de resarcimiento de los daños morales y los valores y principios constitucionales, dentro del marco de la democracia plural y participativa como ámbito existencial imprescindible para que la vida de la persona se pueda desarrollar de modo acorde con su dignidad $y$, consiguientemente, con el libre desarrollo de su personalidad. Y, por otro, con el afloramiento del concepto de solidaridad social, como principio y deber derivado de esa dimensión pública

32 Esa es también la razón por la que, a nuestro juicio, y en referencia al ordenamiento español, el concepto constitucional de persona (cuyos elementos nos vienen proporcionados fundamentalmente por los artículos 10 y 15 de la Constitución) ha de prevalecer sobre el concepto de persona a efectos civiles que ofrecen los artículos 29 y 32 del Código Civil. Al respecto, Alegre MARTínez (2002 a, especialmente pp. 348 y ss., donde se critica el hecho de que el Tribunal Constitucional español, en varias ocasiones, haya formulado un concepto de "persona" tomando como referencia el Código Civil en lugar de explorar las posibilidades que ofrece la propia Constitución para extraer un concepto lo más amplio y favorable posible.

33 En España, baste citar respecto del empleo de esta expresión, los trabajos de Santos Briz (1962), Díez-Picazo (1999), Concepción Rodríguez (1999), Roca I Trias (2000) y CORDERO LOBATO (2000). 
de los daños morales, no por ello incompatible con la fuerte autoconciencia de la individualidad propia de nuestro tiempo (vid. supra, apartado 2$)^{34}$.

\section{CONSIDERACIONES FINALES}

Estas son, pues, (presentadas aquí casi en forma de lluvia de ideas) las líneas generales que aquí pretendíamos desarrollar. La consideración conjunta de todos los elementos que hasta aquí se han ido desgranando, debería servirnos para no quedarnos en el marco teórico de los derechos de la personalidad y los daños morales, sino, más bien, utilizarlo y servirnos de él para confrontarlo con la realidad e intentar contribuir a mejorarla. Esa realidad viene dada, en buena medida (aunque no exclusivamente), por los diversos mecanismos de protección de los derechos de la personalidad (acción por daños morales, protección civil, protección penal, mediación y Justicia de Paz, amparo constitucional, etc.), y por los distintos perfiles que éstos presentan en España y en Latinoamérica, que en ocasiones motivarán la necesidad de las oportunas precisiones terminológicas.

De cara a la deseable eficacia de esos mecanismos de resarcimiento del daño moral en la medida de lo posible, sería deseable, desde luego, una acción que presentara características intermedias entre las diversas existentes, de cara a compaginar la necesaria profundidad analítica y el concurso de expertos en diversas disciplinas, con la imprescindible celeridad del procedimiento. Asimismo, al servicio de dicho objetivo debería estar también la atribución de un mayor protagonismo al principio de equidad: retomarlo y analizarlo debería servir para valorar si con él la sociedad puede obtener resultados más satisfactorios que los que hasta ahora viene obteniendo, y permitiría también desmontar los diversos mitos y connotaciones negativas que se han venido forjando en torno a la misma desde concepciones positivistas, ligándola a la idea de azar, riesgo o arbitrariedad.

${ }^{34}$ Se refiere este principio a la necesaria reacción de la colectividad frente a la vulneración de los derechos de la personalidad de alguno de sus miembros, y al necesario resarcimiento de los daños morales como imperativo de salubridad social. La solidaridad es uno de los "valores superiores" presentes en el artículo 2 de la Constitución venezolana. En la española, artículo 45.2, se habla de la «indispensable solidaridad colectiva» en relación con la utilización racional de los recursos naturales «con el fin de proteger y mejorar la calidad de vida y defender y restaurar el medio ambiente». En un contexto distinto, la solidaridad como principio relativo a la organización territorial del Estado se encuentra en los artículos 2, 138 y 158. 
En definitiva, vista (supra, apartado 3.1) la pluralidad de facetas que se hallan presentes en la idea de personalidad (físicos, psicológicos, sociales, culturales), tendremos que concluir que, si la perspectiva jurídica es sólo una de las posibles a la hora de aproximarnos a los daños morales, también el resarcimiento judicial sería sólo uno de los posibles a la hora de reparar las vulneraciones de los derechos de la personalidad que producen daños morales. Si podemos compartir con MARINA y DE LA VÁlgoma $(2000: 63,61)$ que "la apelación a un tercero - a un juez- para solventar conflictos nos parece un gran progreso" y que la justicia se puede redefinir como "modo legítimo de resolver conflictos", que "pone a salvo los valores fundamentales de una sociedad" frente a la venganza o la ley del más fuerte, no lo es menos que nuevas formas - también de justicia- como la mediación, la Justicia Vecinal o la Justicia de Paz resultan capaces, hoy por hoy, de ofrecer alternativas allí donde el tradicional proceso judicial muestra sus carencias en forma de lentitud o ineficacia.

Se trata, en todo caso, de cuestiones en torno a las cuales hemos pensado que merece la pena seguir reflexionando, y no otra cosa pretenden estas páginas.

Se ha dicho con acierto que la doctrina «debería volver a descubrir los principios, a indicar líneas de conducta, restando al juez y al legislador el hacer referencia a su pensamiento. Demasiadas veces, en cambio, el jurista investigador —especialmente en el campo del Derecho Constitucional- se contenta con ser un descriptor de la jurisprudencia o de la legislación, de modo que sus libros se resuelven en reseñas de jurisprudencia o de legislación. De esta forma, empero, la doctrina abdica de su propia misión» (Pegoraro, 2004: 20-21). Así pues, y en relación con las inquietudes que manifestábamos al principio, deseamos terminar reivindicando el valor y la necesidad de la reflexión doctrinal, más que nunca en los agitados tiempos actuales.

\section{BIBLIOGRAFÍA}

Alegre Martínez, Miguel Ángel (1995): «El artículo 10.1 de la Constitución como deber genérico de respetar la dignidad y los derechos de la persona", Revista General de Derecho, n. ${ }^{\circ}$ 604-605, Valencia, pp. 189-222.

- (1996): La dignidad de la persona como fundamento del ordenamiento constitucional español, Secretariado de Publicaciones de la Universidad de León. 
- (1997): El derecho a la propia imagen, Madrid, Tecnos («Temas clave de la Constitución española»).

- (2002 a): "Apuntes sobre el derecho a la vida en España: Constitución, jurisprudencia y realidad", Revista de Derecho Político, n. ${ }^{\circ}$ 53, UNED, pp. 337-358.

- (2002 b): "Cultura de derechos, deberes y participación», Revista de Derecho del Tribunal Supremo de Justicia de Venezuela, n. ${ }^{\circ}$, 2002, pp. 3-17.

- (2003 a): "Tema IX: La Constitución»; "Tema X: Derechos y libertades»; "Tema XIX: Poder judicial y jurisdicción constitucional», en DE Blas Guerrero, Andrés, Rubio Lara, M. ${ }^{a}$ Josefa, De Andrés Sanz, Jesús (Directores), Teoría del Estado (Unidades didácticas. Ciencias Políticas y Sociología), Madrid, Universidad Nacional de Educación a Distancia (UNED), 2003; pp. 255-298, 299-346, 603-649.

- (2003 b): «Dignidad de la persona y educación en derechos humanos", León Ciencia, Revista de divulgación científica de la Universidad de León, n. ${ }^{\circ}$, primavera 2003, pp. 8-9.

- (2005): «El reconocimiento constitucional de la dignidad humana: significado y alcance» [En Libro Homenaje al Profesor Íñigo Cavero, de próxima aparición].

Alegre Martínez, Miguel Ángel y Luis Jimena Quesada (2005): “La Carta de los Derechos Fundamentales de la Unión Europea tras su integración en el Tratado constitucional: asimetrías, inconsistencias y paradojas", en VV.AA., Colóquio Ibérico: Constituçao europeia. Homenagem ao Doutor Francisco Lucas Pires. Boletim da Faculdade de Direito. Studia Iuridica 84, Ad Honorem-2, Colloquia-14, Universidade de Coimbra, Coimbra Editora, pp. 53-84.

AYLLÓn DíAZ, Jesús (2003): "Los valores o principios inspiradores", en Benito DE CASTRO CID (Dir. y Coord.), Introducción al estudio de los derechos humanos, con la colaboración de Ignacio ARA PINILLA, Narciso Martínez Morán, Jesús Ayllón díaz e Íñigo De Miguel Beriain; Madrid, Editorial Universitas, pp. 147-166.

Ayuso, Miguel (2000): El ágora y la pirámide. Una visión problemática de la Constitución española, Madrid, Criterio Libros.

Beltrán de Heredia y Castaño, José (1976): Construcción jurídica de los derechos de la personalidad, Madrid, Real Academia de Jurisprudencia y Legislación. 
BENDA, Ernesto (2001): «Dignidad humana y derechos de la personalidad", en Benda, Malhofer, Vogel, Hesse, Heyde, Manual de Derecho Constitucional; (Presentación de C. HESSE; edición, prolegomena y traducción de A. López PINA, prólogo de M. A. García HerRerA), Madrid, Marcial Pons, 2. ${ }^{\text {a }}$ edición en castellano, pp. 117-144.

Bilbao UbiLlos, Juan María (1997): La eficacia de los derechos fundamentales frente a particulares: análisis de la jurisprudencia del Tribunal Constitucional, Madrid, Boletín Oficial del Estado/ Centro de Estudios Políticos y Constitucionales. Prólogo de Javier JIMÉNEZ CAMPO.

Biscaretti DI RuffiA, Paolo (1982): Derecho Constitucional, Madrid, Tecnos. Reimp. 1984. Traducción, prólogo y notas de Pablo LuCAS VERDÚ.

Brage Camazano, Joaquín (2004): Los límites a los derechos fundamentales, Madrid, Dykinson ("Constitucional»).

Bustos Pueche, José Enrique (1997): Manual sobre bienes y derechos de la personalidad, Madrid, Dykinson.

CÁndido (Carlos Luis Álvarez) (2001): Qué es la dignidad, Barcelona, Ediciones Martínez Roca.

Carrillo, Marc (2003): El Derecho a no ser Molestado (Información y vida privada), Navarra, Thomson Aranzadi.

Carrillo Salcedo, Juan Antonio (1999): Dignidad frente a barbarie. La Declaración Universal de Derechos Humanos, cincuenta años después, Madrid, Trotta.

CAStÁn ToBeñAs, José (1952): "Los derechos de la personalidad", $R e$ vista General de Legislación y Jurisprudencia, julio-agosto 1952, pp. 5 y ss.

Concepción Rodríguez, José Luis (1999): Derecho de daños, Barcelona, Bosch, 2. ${ }^{a}$ edición.

CORDERo LobATo, Encarna (2000): «Derecho de daños y medio ambiente", en Luis OrTega Álvarez (Dir.), Lecciones de Derecho del medio

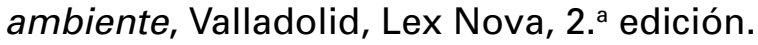

Cotino Hueso, Lorenzo (Coord.) y Remedio SÁnchez FerRiz (Dir.) (2000): Derechos, deberes y responsabilidades en la enseñanza (Un análisis jurídico-práctico a la luz de los dictados constitucionales), Valencia, Generalitat Valenciana, Consellería de Cultura, Educació i Ciència. 
De CAstro CID, Benito (2003): "La clasificación de los derechos», en Benito DE CASTRO CID (Dir. y Coord.), Introducción al estudio de los derechos humanos, con la colaboración de Ignacio ARA PINILLA, Narciso Martínez Morán, Jesús Ayllón díaz e Íñigo De Miguel Beriain; Madrid, Universitas, pp. 243-256.

De Castro y Bravo, Federico (1959): "Los Ilamados derechos de la personalidad", Anuario de Derecho Civil, vol. Il/1959.

De Vega García, Pedro (1985): La reforma constitucional y la problemática del poder constituyente, Madrid, Tecnos ("Temas clave de la Constitución española»).

- (1997): "En torno al concepto político de Constitución», en Miguel Ángel García Herrera (Dir.), El constitucionalismo en la crisis del Estado social, Bilbao, Servicio Editorial de la Universidad del País Vasco, pp. 701-719.

- (1998): «El tránsito del positivismo jurídico al positivismo jurisprudencial en la doctrina constitucional», Teoría y Realidad Constitucional, n. ${ }^{\circ}$ 1, UNED, primer semestre 1998, pp. 65-

DíEz-PıcAzo, Luis (1999): Derecho de daños, Madrid, Civitas.

EsPín, Eduardo (2003): "Los derechos de la esfera personal», en Luis LóPez Guerra, Eduardo Espín, Joaquín García Morillo, Pablo Pérez TREMPS y Miguel SATRústegul, Derecho Constitucional, volumen I, El ordenamiento constitucional. Derechos y deberes de los ciuda-

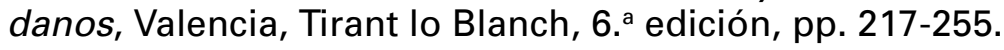

FERnÁNDEZ de Alarcón Medina, Fabián (2005): «Reproducción asistida: de sujeto a objeto", Alba del Tercer Milenio, año II, n. ${ }^{\circ}$ 22, marzo 2005, p. 12.

FERnÁNDEZ Rodríguez, José Julio (2004): Secreto e intervención de las comunicaciones en Internet, Madrid, Thomson Civitas, APDCM (Agencia de Protección de Datos de la Comunidad de Madrid).

FernÁNDEZ Segado, Francisco (1992): «La dimensión axiológica del Derecho constitucional", Cuadernos de la Cátedra Fadrique Furió Ceriol, 2. ${ }^{a}$ época, n. ${ }^{\circ} 1$, Valencia, pp. 15-39.

- (1993): "La teoría jurídica de los derechos fundamentales en la doctrina constitucional», Revista Española de Derecho Constitucional, n. ${ }^{\circ} 39$, pp. 195-147.

- (1995): "La dignidad de la persona en el Ordenamiento constitucional español", Revista Vasca de Administración Pública, n. ${ }^{\circ}$ 43, pp. 49-79. 
Fernández-CARVAJAl GonzÁlez, Rodrigo (1989): «Notas sobre el Derecho Constitucional como 'nuevo Derecho Común'», Anuario de Derecho Constitucional y Parlamentario, n. ${ }^{\circ} 1,1989$, Asamblea Regional de Murcia, Universidad de Murcia, pp. 37-46.

García Cotarelo, Ramón (1988): "La Constitución formal del Estado", en Andrés De Blas y Ramón García Cotarelo, Teoría del Estado, Madrid, UNED, pp. 191-210.

García Cuadrado, Antonio M. ${ }^{a}$ (1998): Derecho Constitucional. La Constitución y las fuentes del Derecho Constitucional, Alicante, Editorial Club Universitario, 4. ${ }^{a}$ edición.

- (2002): El Ordenamiento constitucional (Un enfoque histórico y formal de la teoría de la Constitución y de las fuentes del Derecho), Alicante, Editorial Club Universitario.

GaRcía GarcíA, Clemente (2003): El derecho a la intimidad y dignidad en la doctrina del Tribunal Constitucional, Universidad de Murcia, Servicio de Publicaciones, (Colección «Estudios de Derecho»).

García TorRes, Jesús y Antonio Jiménez-Blanco (1986): Derechos fundamentales y relaciones entre particulares: la Drittwirkung en la jurisprudencia del Tribunal Constitucional, Madrid, Civitas ("Cuadernos Civitas»).

GonzÁlez PÉREZ, Jesús (1986): La dignidad de la persona, Madrid, Civitas.

- (2005): "Prólogo» a Tomás Prieto Álvarez, La dignidad de la persona. Núcleo de la moralidad y el orden públicos, límite al ejercicio de libertades públicas, Pamplona, Aranzadi, Thompson Civitas, Caja de Burgos, pp. 17-20.

GutiÉRREZ GutiÉRREZ, Ignacio (2004): "La dignidad quebrada», Teoría y Realidad Constitucional, n. ${ }^{\circ} 14$, UNED, segundo semestre 2004, pp. 331-343.

Hernando García, Pedro J. (1993): «Problemática jurídico-constitucional sobre la libre disposición de la vida humana: la eutanasia», en Escritos jurídicos en memoria de Luis Mateo Rodríguez, (presentación de Juan Manuel Alegre Ávila y Juan Enrique VArona Alabern, prólogo de Luis MARTín ReBOLLO), Universidad de Cantabria, Facultad de Derecho. Tomo I: Derecho Público, pp. 251-279.

Herrero-Tejedor, Fernando (1994): Honor, intimidad y propia imagen, Madrid, Colex, 2. ${ }^{a}$ edición. 
HorN, Hans Rudolf (2004): "Generaciones de derechos fundamentales en el Estado constitucional cooperativo. Contribuciones iberoamericanas al constitucionalismo", Anuario Iberoamericano de Justicia Constitucional, n. ${ }^{\circ}$ 8, 2004, pp. 251-288. Traducción: Joaquín Brage Camazano.

Jimena QuesadA, Luis (2004): "La Carta Social Europea como instrumento de democracia social en Europa y España», en Luis JIMENA Quesada (Coord.), Miguel Ángel Alegre Martínez, Régis Brillat, JeanFrançois FlaUSS, Teresa FREIXES SANJUÁN, Escritos sobre derecho europeo de los derechos sociales, Valencia, Tirant lo Blanch ("Propuestas") y Universitat de València, 2004, pp. 137-190.

- (2005): «El conocimiento del ordenamiento constitucional: condición necesaria de calidad del sistema educativo", [en Libro Homenaje al Profesor Íñigo Cavero, próxima publicación...].

Jimena QuesadA, Luis y Miguel Ángel Alegre Martínez (2005): Los retos de la Unión Europea como retos del Derecho Constitucional español (Reflexiones sobre el Tratado Constitucional), Madrid, Biblioteca Nueva. (En prensa).

JuAN PABlo II (2004): "Mensaje de Su Santidad Juan Pablo II para la Jornada Mundial del Emigrante y del Refugiado», Cáritas, n. ${ }^{\circ} 452$, septiembre 2004, pp. 5-6.

Julio EstradA, Alexei (2000): La eficacia de los derechos fundamentales entre particulares, Universidad Externado de Colombia.

LANDA ArRoyo, César (2002): "Dignidad de la persona humana», Cuestiones constitucionales. Revista Mexicana de Derecho Constitucional, n. ${ }^{\circ} 7$.

Lucas Murillo de la Cueva, Pablo (1991): El derecho a la autodeterminación informativa (Protección de datos personales frente al uso de la informática), Madrid, Tecnos («Temas clave de la Constitución española»).

Lucas Verdú, Pablo (1994): La Constitución en la encrucijada (Palingenesia luris Politici), (Discurso de recepción, con contestación de Miguel Herrero de Miñón), Madrid, Real Academia de Ciencias Morales y Políticas.

- (1995): "Intimidad y dignidad humana», Prólogo a Carlos RUIZ MIGUEL, La configuración constitucional del derecho a la intimidad, Madrid, Tecnos, 1995. 
Mago Bendahán, Óscar (1995): El Juez de Paz y su Comunidad. Una utopía realizada (Ensayo sobre los Jueces de Paz y los principios básicos aplicables a la justicia vecinal hispano americana, con referencia al caso de Venezuela), Caracas, Constitución Activa («Breviarios del Nuevo Derecho»).

- (1998): El amparo constitucional civil (Un enfoque no conformista), Caracas, Constitución Activa ("Breviarios del Nuevo Derecho»).

- (2000): Guía completa de la Constitución 1999 de la República Bolivariana de Venezuela, Caracas-Venezuela, Paredes Editores, Universidad Pedagógica Experimental Libertador, Constitución Activa.

MARINA, José Antonio (2003): "¿Jugando a ser dioses?», El Mundo, 25 de abril de 2003.

- (2004): Aprender a vivir, Barcelona, Ariel.

MARINA, José Antonio y María De LA VÁlgoma (2000): La lucha por la dignidad (Teoría de la felicidad política), Barcelona, Anagrama.

MARTíneZ-PuJALTE, Antonio-Luis (1995): "Hacia un concepto constitucional de persona", en Cuadernos Constitucionales de la Cátedra Fadrique Furió Ceriol, n. ${ }^{\circ}$ 11-12, Valencia, pp. 135-153.

MATEO PARDo, Regino (1993): "La 'dignidad de la persona humana' y su significación en la Constitución española de 1978 a través de la jurisprudencia del Tribunal Constitucional», en Escritos jurídicos en memoria de Luis Mateo Rodríguez, (presentación de Juan Manuel Alegre Ávila y Juan Enrique VARONA Alabern, prólogo de Luis Martín RebolLo), Universidad de Cantabria, Facultad de Derecho. Tomo I: Derecho Público, pp. 341-358.

Mayor Zaragoza, Federico (2003): "Otro mundo es posible», El País, 26 mayo 2003.

MolAs, Isidre (2003): Derecho Constitucional, Madrid, Tecnos, 2. ${ }^{\text {a edi- }}$ ción.

NARANJo de la Cruz, Rafael (2000): Los límites de los derechos fundamentales en las relaciones entre particulares: la buena fe, Madrid, Boletín Oficial del Estado/ Centro de Estudios Políticos y Constitucionales. Prólogo de Ángel Rodríguez.

NombelA, César (2005): "Vida humana y progreso biomédico: un diálogo sobre valores", $A B C, 14$ de abril de 2005, p. 3.

Oliver Araujo, Joan (2003): La Constitución día a día, Valencia, Tirant lo Blanch ("Alternativa»). Prólogo de Jorge De Esteban. 
Peces-Barba Martínez, Gregorio (1984): Los valores superiores, Madrid, Tecnos ("Temas Clave de la Constitución Española»).

(2002): La dignidad de la persona desde la Filosofía del Derecho, Madrid, Dykinson - Instituto de Derechos Humanos «Bartolomé de las Casas", Universidad Carlos III (Cuadernos "Bartolomé de las Casas").

- (2003): "Europa y la dignidad humana», El País, 11 de junio de 2003.

- (2004): Lecciones de Derechos Fundamentales (con la colaboración de Rafael De Asís Roig y María del Carmen BARRAnco Avilés), Madrid, Dykinson (Colección "Derechos Humanos y Filosofía del Derecho".

Pegoraro, Lucio (2001): «El método en el Derecho Constitucional: la perspectiva desde el Derecho Comparado", Revista de Estudios Políticos (Nueva Época), n. 112, 2001, pp. 9-26. Traducción: Daniel BERZOSA LÓPEZ.

- (2002): "Las funciones subsidiarias de la comparación en el estudio de los ordenamientos federales y del gobierno local", Revista de Estudios Políticos (Nueva Época), n. ${ }^{\circ} 117,2002$, pp. 35-48. Traducción: Alberto Anguita Susí; supervisión: Jorge LozANo MiRALLes.

- (2004): "Prólogo" a José Julio FERnÁNDEZ RodrígueZ, Secreto e intervención de las comunicaciones en Internet, Madrid, Thomson Civitas, APDCM (Agencia de Protección de Datos de la Comunidad de Madrid), pp. 17-28.

PÉREz RoYo Javier (1996): «El Derecho Constitucional en la formación del jurista", Revista Española de Derecho Constitucional, n. ${ }^{4} 46,1996$, pp. 39-60).

Prieto Álvarez, Tomás (2005): La dignidad de la persona. Núcleo de la moralidad y el orden públicos, límite al ejercicio de libertades públicas, Pamplona, Aranzadi, Thompson Civitas, Caja de Burgos. Prólogo de Jesús GonZÁlez PÉreZ.

Real Academia Española (1984): Diccionario de la Lengua Española, Madrid, 20. a edición.

REVENGA SÁNCHEZ, Miguel (2002): "Sobre (viejos) modelos de Justicia Constitucional y creación de (nuevos) Derechos", Revista Española de Derecho Constitucional, n. ${ }^{\circ}$ 64, 2002, pp. 99-110.

Roca I TRIAS, Encarna (2000): Derecho de daños: Textos y materiales. Con la colaboración de Ana LATORRE ARMERO. Valencia, Tirant lo Blanch. 3. ${ }^{a}$ edición. 
Rodríguez Palop, María Eugenia (2002): La nueva generación de Derechos Humanos. Origen y justificación, Madrid, Universidad Carlos III y Editorial Dykinson.

Rodríguez-ZAPATA, Jorge (1996): Teoría y práctica del Derecho Constitucional, Madrid, Tecnos.

RoJAs, Enrique (2005): "¿Cómo es una personalidad inmadura?», $A B C$, 19 de febrero de 2005, p. 3.

RoLLA, Giancarlo (2002): "El valor normativo del principio de la dignidad humana. Consideraciones en torno a las constituciones iberoamericanas", Anuario Iberoamericano de Justicia Constitucional, n. ${ }^{\circ} 6$, pp. 463-489. Traducción: Daniel BeRzosA LóPEZ.

Romero Coloma Aurelia (1985): Los bienes y derechos de la personalidad, Madrid, Trivium.

Ruiz Miguel, Carlos (1995 a): La configuración constitucional del derecho a la intimidad, Madrid, Tecnos ("Ciencias jurídicas»).

— (1995 b): «El derecho a la intimidad informática en el ordenamiento español", Revista General de Derecho, n. ${ }^{\circ}$ 607, 1995.

- (1995 c): «El significado jurídico del principio de la dignidad de la persona en el ordenamiento español», en XXV Jornadas chilenas de Derecho Público (17 al 19 de noviembre de 1994), Valparaíso, EDEVAL, Tomo II, pp. 101-123).

RuIZ-GimÉnEZ CoRTÉS, Joaquín (1997): "Artículo 10. Derechos fundamentales de la persona" (con la colaboración de Icíar RUIZ-GIMÉNEZ Arrieta), en Óscar Alzaga VillaAmil (Dir.), Comentarios a la Constitución española de 1978, Madrid, Cortes Generales - Editoriales de Derecho Reunidas. Tomo II, pp. 37-107.

SÁNCHEZ FERRIZ, Remedio (1995): Estudio sobre las libertades, Valencia, Tirant lo Blanch ("Alternativa»), 2. ${ }^{\text {a edición. }}$

- (2000): "Prólogo" a María Vicenta García SoRIANo, Jueces y magistrados en el proceso electoral, Madrid, Centro de Estudios Políticos y Constitucionales («Cuadernos y Debates»), pp. 17-22.

SÁNCHEZ FERRIZ, Remedio y Luis JIMENA QueSAdA (1995): La enseñanza de los derechos humanos, Barcelona, Ariel.

Santos BrIZ, Jaime (1962): Derecho de daños, Madrid, Ed. Revista de Derecho Privado. 
SARTORI, Giovanni (1999): "La ingeniería constitucional y sus límites", Teoría y Realidad Constitucional, n. ${ }^{\circ} 3$, UNED, pp. 79-87. Versión española de Santiago SÁNCHEZ GonZÁLEZ.

SeIJAS VILLADANGos, Esther (2005): Los derechos de las personas mayores, Madrid, Boletín Oficial del Estado ("Conoce tus derechos»).

SORIANO, Ramón (1987): “¿Es iusnaturalista la Constitución de 1978?», Revista de las Cortes Generales, n. ${ }^{\circ} 12$, pp. 109-159.

SPAEMANN, Robert (1988): "Sobre el concepto de dignidad humana", Persona y Derecho, n. ${ }^{\circ} 19$, pp. 13-33. Traducción: Daniel INNERARITY.

Tocoueville, Alexis de (1840): La democracia en América, 2, Madrid, Alianza Editorial, ("Libro de Bolsillo, Ciencia Política»), 1980 y 2002; 1. ${ }^{a}$ reimpresión, 2004. Traducción: Dolores SÁNCHEZ DE ALEU.

Von MüNCH, Ingo (1982): "La dignidad del hombre en el Derecho constitucional", Revista Española de Derecho Constitucional, n. ${ }^{\circ}$, pp. 933. Traducción: Jaime NicolÁs MuÑIz.

Title:

"Constitutional recognizance of dignity, individuality and the rights of personality".

\section{Summary:}

1. Previous considerations and general proposition. 2. The constitutionalized individuality based on the dignity of the person. 2.1. The profile and the dimension of individuality. 2.2. Individuality and the progressive recognition of rights. 3 . The consideration of moral tort as a damage to integrity and the free development of personality. 3.1. Contextualization of the moral tort. 3.2. Methodological consequences. 4. Final considerations.

\section{Palabras clave:}

Dignidad de la persona. Derechos de la personalidad. Daños morales. Libre desarrollo de la personalidad. Libertad. Integridad moral. Individualidad. Constitucionalización y reconocimiento de los derechos. Generaciones de derechos. Derecho comparado. Enfoque interdisciplinar. 


\section{Key words:}

Dignity of the person. Rights of personality. Moral torts. Free development of personality. Freedom. Moral integrity. Individuality. Constitutionalization and recognition of rights. Generation of rights. Comparative laws. Interdisciplinary outlook.

\section{Resumen:}

El trabajo trata de mostrar la conexión entre los daños morales y la lesión de los derechos de la personalidad, que encuentran su raíz en el libre desarrollo de la personalidad, fundamentado a su vez en la dignidad humana. Todos los derechos que son imprescindibles para el libre desarrollo de la personalidad son derechos de la personalidad, y están vinculados a la libertad y a la integridad moral, porque cuando se lesionan estos derechos, siempre se causa, al menos, un daño moral. Por eso, el reconocimiento de la libertad y la integridad es una exigencia mínima y básica que debe acompañar a la constitucionalización de los derechos de la personalidad.

Esa constitucionalización intenta proteger una serie de bienes jurídicos ligados a la personalidad (vida, integridad, libertad, honor, imagen, etc.). Las conexiones entre dichos bienes y su fundamento común nos permiten reducirlos a uno solo: la individualidad.

En este mismo contexto, la conexión entre dignidad y personalidad nos recuerda que la persona no es un objeto, y se traduce en la necesidad de proteger la individualidad de la persona en sus diversas facetas o dimensiones (humanidad, irrepetibilidad, igualdad, universalidad, integridad).

Los ordenamientos jurídicos han ido respondiendo a esta exigencia mediante la paulatina constitucionalización e internacionalización de los derechos y libertades como fruto de una conciencia cada vez mayor de la individualidad; ello ha permitido hablar de sucesivas "generaciones de derechos" según un criterio cronológico, que ha de ser completado con las ideas de indivisibilidad y universalidad de los derechos humanos.

Por otra parte, precisamente porque los derechos se insertan en el ordenamiento jurídico (del que la Constitución forma parte), y por la importancia de los bienes jurídicos protegidos a través de su reconocimiento, la reflexión sobre los derechos de la personalidad y sobre los diversos medios de garantía de los mismos, debe llevarse a cabo a través de un enfoque interdisciplinar que los contemple desde perspecti- 
vas complementarias. Ello implica, entre otras cosas, la utilización conjunta de las perspectivas civil y constitucional, necesaria en la medida en que la víctima de un daño moral es quien mejor conoce su intensidad $y$, por tanto, debe poder participar en el diseño del resarcimiento que más le conviene frente a unos daños morales siempre difíciles de probar y de cuantificar.

Además, mediante ese enfoque interdisciplinar (más allá, incluso, del ámbito jurídico-procesal) en el tratamiento de las lesiones que ocasione un daño moral, se logrará una protección integral de la persona (de sus bienes, intereses, necesidades, sentimientos) que vaya más allá de la mera protección de sus derechos. En todo caso, el Derecho Constitucional deberá estar presente en esa respuesta jurídica frente a los daños morales, sobre todo porque éstos presentan, junto con su vertiente privada, una importante componente de orden público.

\begin{abstract}
:
This essay intends to show the relation between moral tort and the damage caused to the rights of the personality which sinks its roots in the free development of personality, at the same time based on the dignity of the human being.
\end{abstract}

All the rights which can not be sidestepped in the free development of personality are the rights of the personality, and are related to the freedom and the moral integrity of a person because, when damage is caused to any of those rights, at least a moral damage is always caused too. This is why the recognition and the integrity is a minimal and basic exigency that must go hand in hand with the constitutionalization of the rights of personality

That constitutionalization intends the protection of a series of juridical commodities, conveniences, related to personality, such as life, integrity, freedom, honor, image, etc.

The connection between said goods and their common fundament allows us to reduce individuality to one entity.

In this same context, the connection between dignity and personality reminds us that a person is not an object which means that it is necessary to protect the individuality of a person and its various facets or dimentions, such as humanity, universality, integrity, irrepeatability, equalness. 
The juridical ordinances have been responding to this exigency through a slow constitutionalization and internationalization of the rights and liberties as a product of a growing conscience of the individuality; this has allowed speaking of successive "generation of rights" according to a chronological standard that will have to be completed with the ideas of indivisibility and universality of human rights.

On the other hand, precisely because the rights are inserted on the juridical ordainment, of which de Constitution is a part thereof, and because of the importance of the juridical goods protected through their recognition, the reflexions on the rights of personality and on the ways that guarantee the same they should be carried out through an interdisciplinary outlook which will place them in complimentary perspectives necessary in as much as it is the victim of a moral damage who knows better of its intensity and therefore he should be able to participate in what way he should be indemned in the face of moral damage always difficult to prove and quantify.

Beside, through that interdisciplinary focusing (beyond the juridical procedural law environment) in the treatment of the injuries caused by a moral damage, an integral protection of the person can be attained. This also covers the protection of his property, interests, necessities and sentiments, which means more than the simple protection of his human rights. In all cases the Constitutional Law should be present in the juridical focusing of moral damages, specially because they present besides its private law origin, an important meaning of public order. 